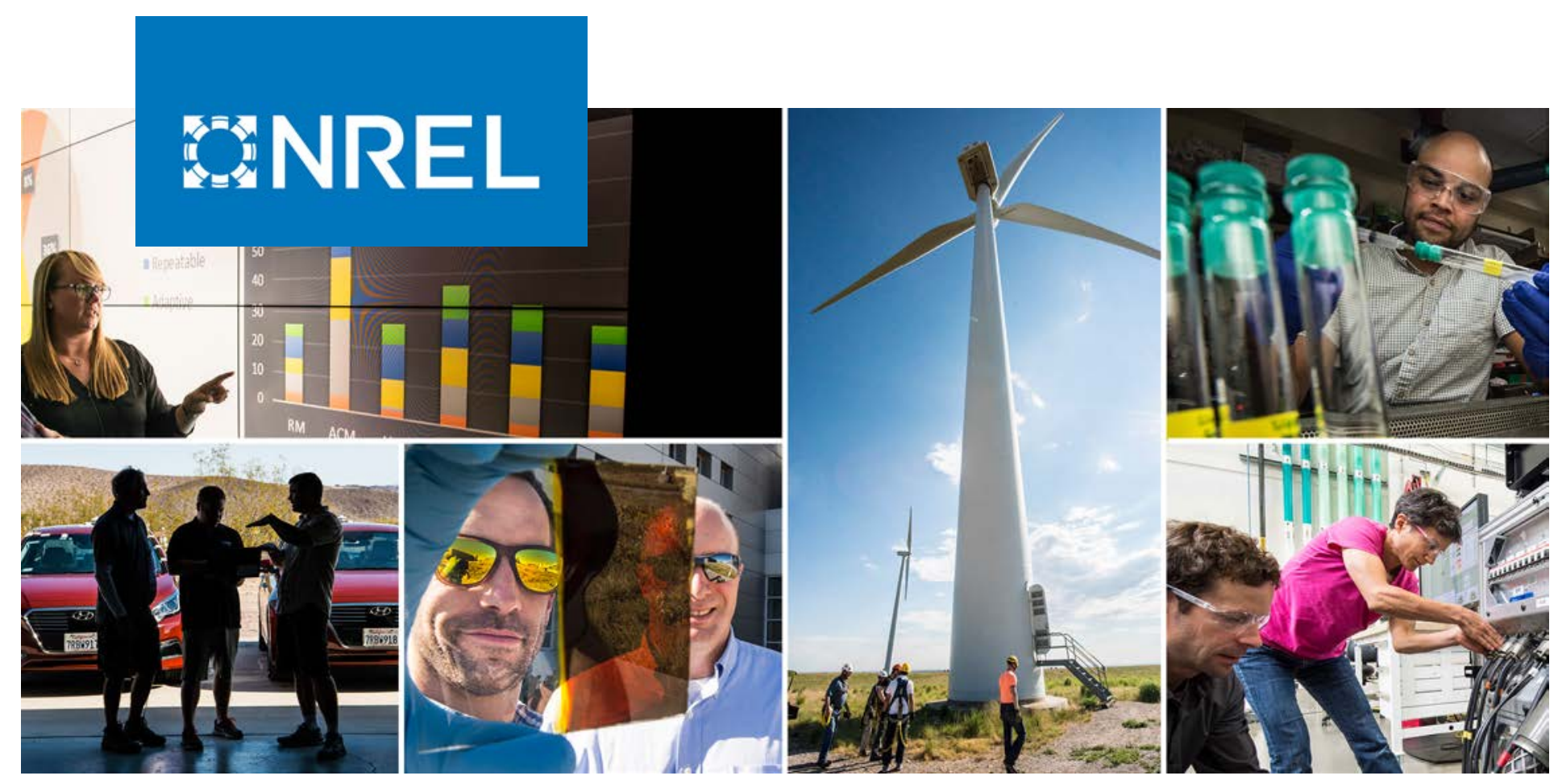

\title{
Cross-Border Energy Trade between Nepal and India: Assessment of Trading Opportunities
}

Brendan McBennett, Amy Rose, David Hurlbut, David Palchak, and Jaquelin Cochran

National Renewable Energy Laboratory

NREL is a national laboratory of the U.S. Department of Energy

Office of Energy Efficiency \& Renewable Energy

Operated by the Alliance for Sustainable Energy, LLC

This report is available at no cost from the National Renewable Energy Laboratory (NREL) at www.nrel.gov/publications.
Technical Report

NREL/TP-6A20-72066

April 2019 


\title{
GNREL
}

\section{Cross-Border Energy Trade between Nepal and India: Assessment of Trading Opportunities}

\author{
Brendan McBennett, Amy Rose, David Hurlbut, \\ David Palchak, and Jaquelin Cochran
}

National Renewable Energy Laboratory

\author{
Suggested Citation \\ McBennett, Brendan, Amy Rose, David Hurlbut, David Palchak, and Jaquelin Cochran. \\ 2019. Cross-Border Energy Trade Between Nepal and India: Assessment of Trading \\ Opportunities. Golden, CO: National Renewable Energy Laboratory. \\ NREL/TP-6A20-72066. https://www.nrel.gov/docs/fy19osti/72066.pdf.
}

NREL is a national laboratory of the U.S. Department of Energy Office of Energy Efficiency \& Renewable Energy Operated by the Alliance for Sustainable Energy, LLC

This report is available at no cost from the National Renewable Energy Laboratory (NREL) at www.nrel.gov/publications.

Contract No. DE-AC36-08GO28308
Technical Report NREL/TP-6A20-72066 April 2019

National Renewable Energy Laboratory 15013 Denver West Parkway Golden, CO 80401

303-275-3000 • www.nrel.gov 


\section{NOTICE}

This work was authored by the National Renewable Energy Laboratory, operated by Alliance for Sustainable Energy, LLC, for the U.S. Department of Energy (DOE) under Contract No. DE-AC36-08G028308. Funding provided by U.S. Department of State's Bureau of South and Central Asian Affairs Regional Connectivity Program. The views expressed herein do not necessarily represent the views of the DOE or the U.S. Government.

This report is available at no cost from the National Renewable Energy Laboratory (NREL) at www.nrel.gov/publications.

U.S. Department of Energy (DOE) reports produced after 1991 and a growing number of pre-1991 documents are available free via www.OSTI.gov.

Cover Photos by Dennis Schroeder: (clockwise, left to right) NREL 51934, NREL 45897, NREL 42160, NREL 45891, NREL 48097, NREL 46526.

NREL prints on paper that contains recycled content. 


\section{Abstract}

Recent developments in India and Nepal highlight new opportunities for increased cross-border energy trade (CBET). This study builds on several prior analyses of CBET in South Asia to explore potential trading opportunities among India, Nepal, Bangladesh, and Bhutan. Uniquely, this study uses a detailed 1-year, 1-hour resolution unit commitment and economic dispatch model of the South Asia power system in the year 2022 to examine the technical and economic impacts of CBET under different assumptions about hydropower development in Nepal and regional trade agreements. The study finds that although Nepal might have the physical capacity to increase annual exports to India if development of domestic hydropower is accelerated (to 4,500 megawatts ), much of this increase would be uneconomic to export if current market inefficiencies between the two countries remain. But the economics of trade can improve dramatically with institutional changes. If market and system operating rules are revised to treat transactions with Nepal the same as transactions between Indian states, our findings suggest that annual net exports to India could increase threefold (to 9.0 terawatt hours), hydro curtailment in Nepal would decrease, and production costs for electricity in both countries would fall \$359 million. These factors - the level of hydropower development in Nepal and the ease of crossborder trade - are the biggest drivers of potential CBET in South Asia. The study also examines the impact of CBET on renewable energy development in India, a supply contract between Nepal and Bangladesh, and fully coordinated market operations across Bangladesh, Bhutan, India's eastern region, and Nepal. Although this study does not provide a complete characterization of system operations within each South Asia country, it does capture many previously unconsidered intertemporal operational constraints. Additional work can include more detailed representations of the Bhutan and Bangladesh power systems and alternative trading arrangements with these countries, which could be especially fruitful in light of the benefits measured in this study. 


\section{Acknowledgments}

The authors are greatly indebted to the following individuals for sharing their thoughtful feedback throughout the project: Jeff Ficken and Olivier Garaud (U.S. Department of State); Monali Hazra, Priya Sreedharan, Michael Boyd, and Shanker Khagi (U.S. Agency for International Development); Manish Keshari and Narendra Sathvik (POWERGRID); and Mohit Joshi.

We also thank Brady Stoll from the National Renewable Energy Laboratory for her reviews and Britton Marchese for the technical edit to this paper. Any errors or omissions are solely the responsibility of the authors.

This analysis was funded by the U.S. Department of State's Bureau of South and Central Asian Affairs Regional Connectivity Program. 


\section{List of Acronyms}

$\mathrm{ACE}$

BAU

BBIN

CBET

$\mathrm{CO}$

DA

EIM

GW

INR

ISO

$\mathrm{kV}$

LDC

LMP

MW

NEA

NREL

POSOCO

RE

ROR

RT

UC\&ED area control error

business as usual

Bangladesh, Bhutan, India, Nepal

cross-border energy trade

coordinated operations

day-ahead

energy imbalance market

gigawatt

Indian rupee

independent system operator

kilovolt

load dispatch center

locational marginal price

megawatt

Nepal Electricity Authority

National Renewable Energy Laboratory

Power System Operation Corporation, Ltd.

renewable energy

run-of-river

real time

unit commitment and economic dispatch 


\section{Executive Summary}

Recent developments on both sides of the border between India and Nepal highlight new opportunities for increased cross-border energy trade (CBET). First, CBET can promote coordinated use of energy resources and potentially reduce the need for investments in new infrastructure to meet anticipated strong growth in electricity demand in both countries. Second, projected growth in Nepal's hydroelectric generating capacity presents an opportunity for hydropower developers to increase return on investments through export sales while also giving neighboring states in India access to low-cost hydropower. Third, coordinated regional trade can facilitate renewable energy (RE) integration by increasing access to resources available for balancing.

This study explores potential CBET from an operations perspective among India, Nepal, Bangladesh, and Bhutan by examining the technical and economic impacts of trade on both systems in the year 2022. Our primary tool is a production cost model, which simulates optimal unit commitment and economic dispatch of the system subject to physical, operational, and market constraints. This study finds significant opportunities for increased trade between Nepal and India. These opportunities depend highly both on the level of hydropower expansion in Nepal and the level of coordination for power exchanges between the two countries.

\section{Increased hydropower development in Nepal decreases production costs by $\$ 106$ million annually. ${ }^{1}$}

Under an accelerated hydroelectric investment scenario, annual exports from Nepal to India increase by $60 \%$ and production costs in the combined India and Nepal system could fall by $0.3 \%$ compared to a low investment scenario. However, existing coordination barriers between the two countries limit further exports, and $45 \%$ of available hydropower energy from Nepal is not used in the accelerated development scenario.

\section{Combining increased coordination with accelerated hydropower development provides} the largest savings to both countries.

Coordinating operations between Nepal and India, such that trade with Nepal is institutionally no different than trade between Indian states, can maximize the use of Nepal's hydropower resources. Increased coordination enables Nepal to become a net exporter of hydropower in the wet and dry seasons and also expands economic opportunities for Nepal to compete with India's western region as a supplier of energy to the northern region. As a result, combining increased coordination with accelerated hydropower development could decrease annual production costs by $\$ 462$ million annually, or $1.3 \%$, compared to a base case with uncoordinated operations and low hydropower development.

\section{Access to Nepal's hydropower and increased coordination has little effect on wind and solar integration in India.}

Increased hydropower exports from Nepal to India have little effect on wind and solar integration in India, largely because most of Nepal's new hydropower is run-of-river, which lacks storage. On the other hand, increased wind and solar deployment in India can reduce the potential market

\footnotetext{
${ }^{1}$ Currency values are converted to U.S. dollars except where otherwise noted. The assumed exchange rate is 65 Indian rupees to 1 U.S. dollar.
} 
for Nepal's hydropower exports unless institutional barriers to trade are reduced through coordinated operations.

There is adequate demand for Nepal's exports without an additional supply contract with Bangladesh.

Increased levels of coordination, including a supply contract with Bangladesh, does not materially change Nepal's generation or exports because the Indian market absorbs all available hydropower exports from Nepal. The added supply contract essentially redirects power flows internally within India, particularly from coal generation.

Increased coordination across Bangladesh, Bhutan, Nepal, and India's eastern region (BBIN) can further reduce production costs.

Costs per unit generated in the combined region can decrease by $5.4 \%$ if system operations were more coordinated compared to current levels of coordination. With increased internal coordination, the BBIN region also exports more power to the rest of India. If operations are fully consolidated within an independent system operator, an additional $1.1 \%$ savings are possible.

Although the study identifies many previously unconsidered impacts on CBET between India, Nepal, Bhutan, and Bangladesh, including local impacts in different Indian states and regions and intertemporal operational constraints, it does not provide a complete characterization of system operations within the entire region. Future work could include detailed modeling of the Bhutan and Bangladesh power systems to examine the impact of CBET on these systems in greater detail. Complementary analysis could identify policy and regulatory pathways to remove nontechnical barriers to CBET and capture the benefits identified in this study. 


\section{Table of Contents}

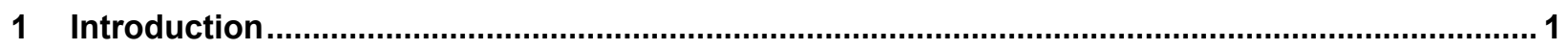

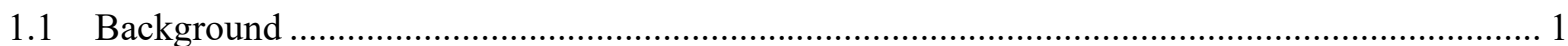

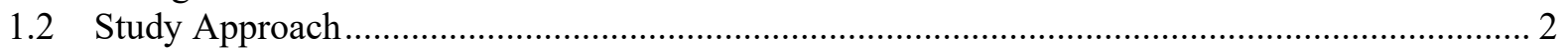

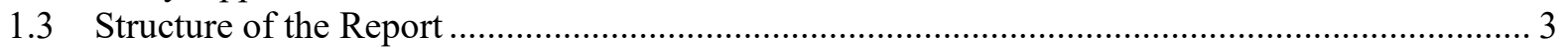

2 Study Scenarios, Modeling Methodology, and Assumptions................................................ 4

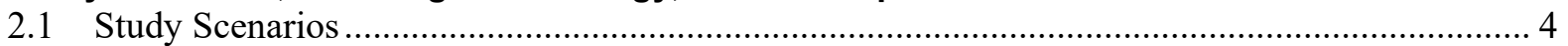

2.1.1 Hydro Buildout........................................................................................ 4

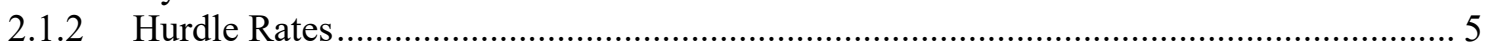

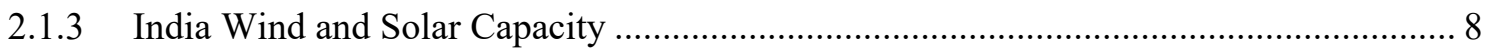

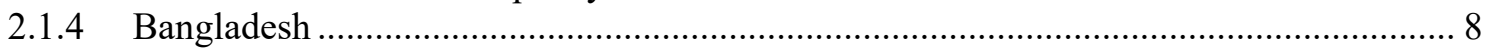

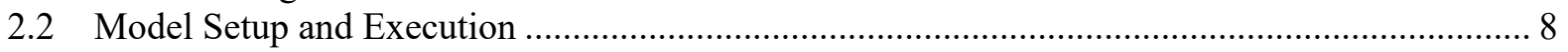

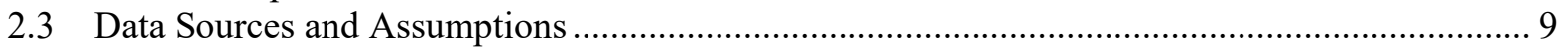

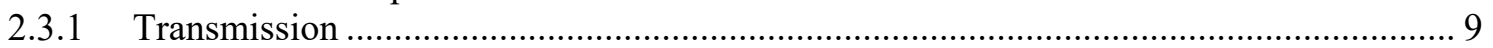

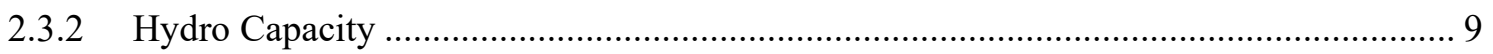

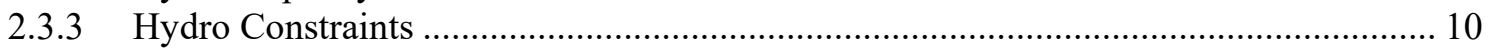

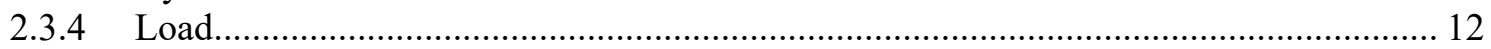

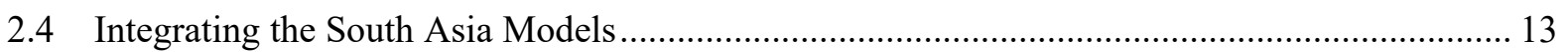

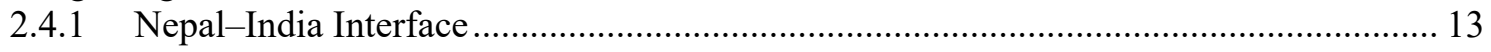

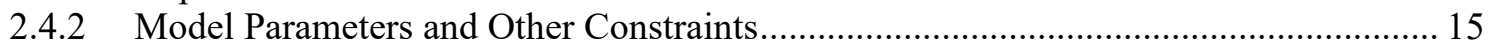

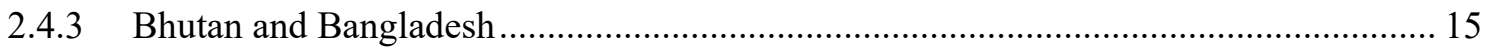

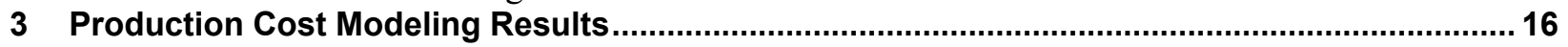

3.1 Increased Nepal Hydropower with No Other Changes ......................................................... 16

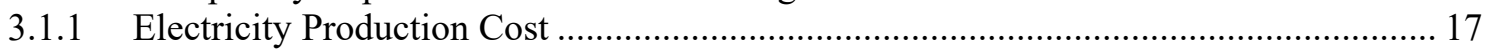

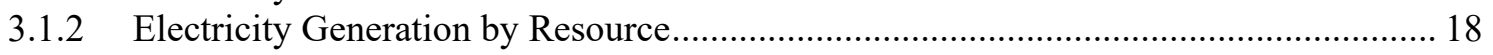

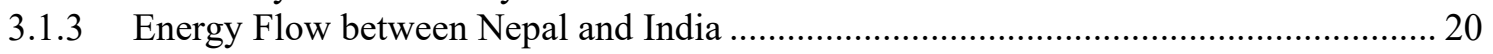

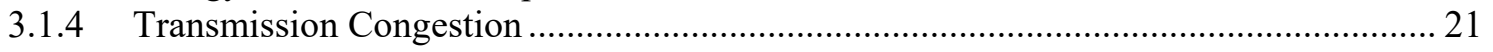

3.2 Increased Nepal Hydropower with Coordinated Operations.................................................. 22

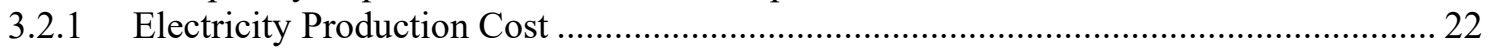

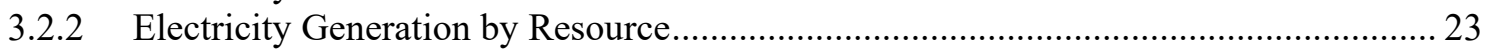

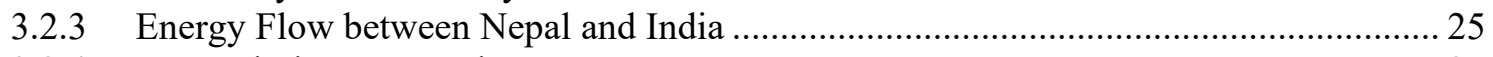

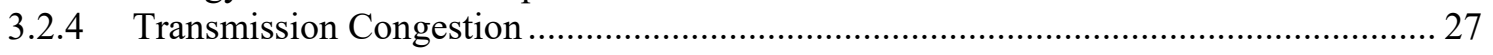

3.3 Nepal Hydropower with Renewable Energy Integration in India ........................................... 27

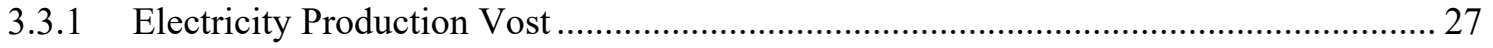

3.3.2 Electricity Generation by Resource and RE Curtailment ............................................. 28

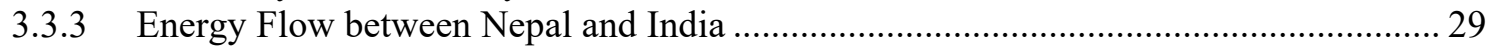

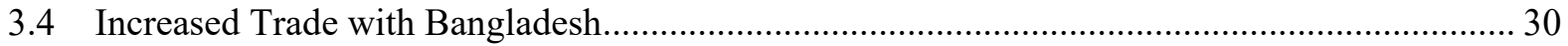

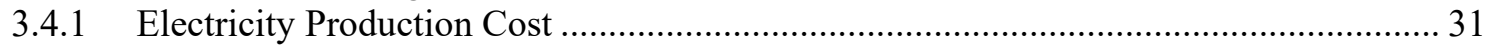

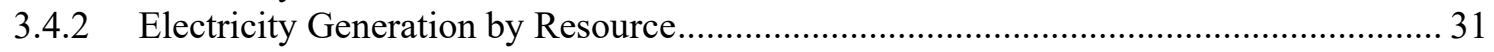

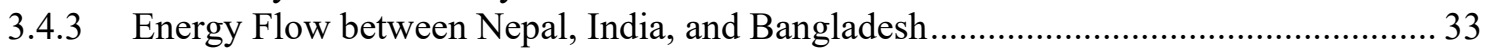

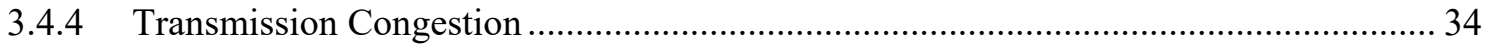

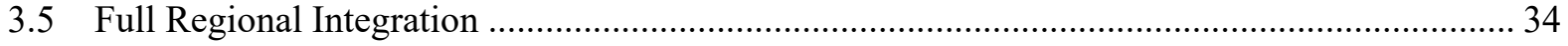

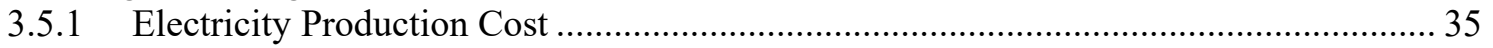

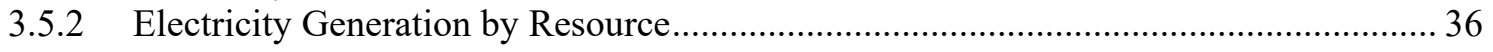

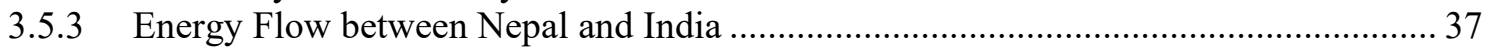

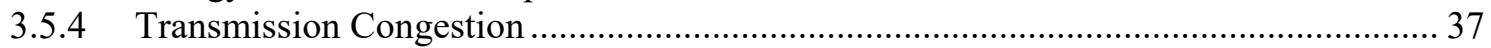

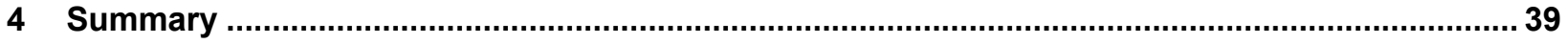

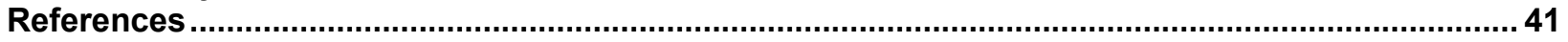




\section{List of Figures}

Figure 1. Methodology for determining Nepal's 2022 hydro generation capacity................................. 10

Figure 2. Average monthly capacity factor by major Nepalese river basin, capacity weighted ................. 11

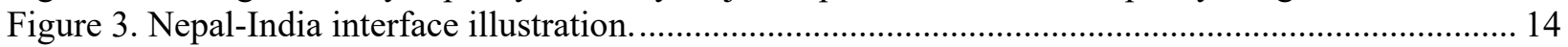

Figure 4. Price in Bihar and Uttar Pradesh relative to hurdle rate on Nepal's exports by season, Base -

BAU and High Build - BAU scenarios. ......................................................................... 18

Figure 5. Nepal hydro generation and curtailment by resource type, Base-BAU, and High Build-BAU

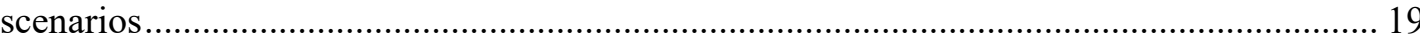

Figure 6. Difference in generation in the High Build-BAU scenario compared to the Base-BAU scenario, by region.

Figure 7. Average hourly net interchange between Nepal and India by Indian state, Base-BAU, and High

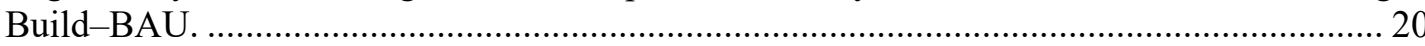

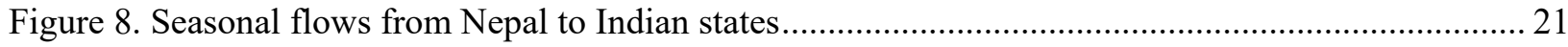

Figure 9. Production cost savings for Nepal and India due to Coordinated Operations, High Build ......... 23

Figure 10. Nepal hydro generation and curtailment by resource type, all scenarios ............................... 24

Figure 11. Difference in generation, by fuel type, due to Coordinated Operations for both hydro capacity

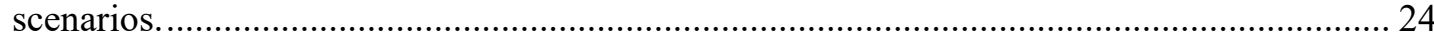

Figure 12. Average hourly net interchange between Nepal and India by Indian state, all scenarios......... 26

Figure 13. Generator dispatch and load in Nepal on March 15, Base scenario with and without

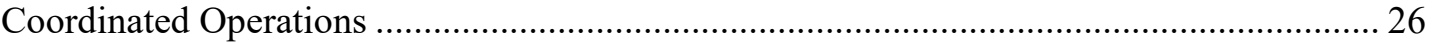

Figure 14. Annual generation in Nepal and India by resource type, all scenarios .................................. 28

Figure 15. Average hourly net interchange between Nepal and Indian state, High Build-CO-Low RE vs.

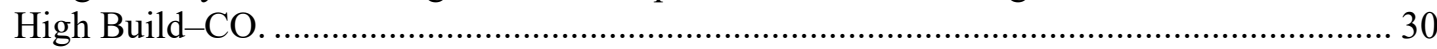

Figure 16. Major changes in generation by region and state with an added Bangladesh supply contract

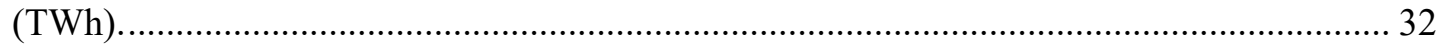

Figure 17. Major changes to India's internal annual interstate flows and generation after adding

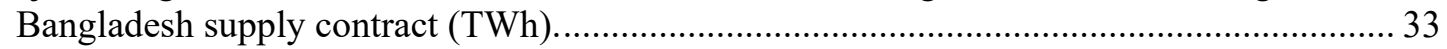

Figure 18. Change in annual generation for the BBIN region and the rest of India under different wheeling

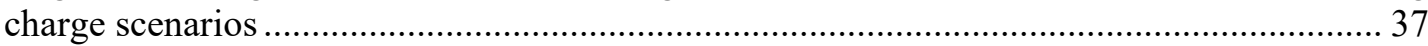




\section{List of Tables}

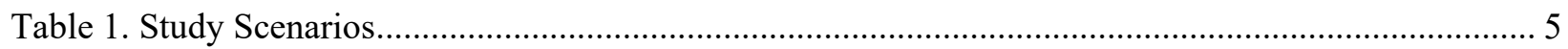

Table 2. Hurdle Rates Associated with Different Scenarios.................................................................... 6

Table 3. Basic Information on the Modeled 2022 Nepal Transmission Network..................................... 9

Table 4. Nepal 2022 Database Hydro Capacity by Generator Type, Base/High Build Scenario (MW) .... 11

Table 5. Nepal 2022 Database Hydro Constraints by Generator Type .................................................... 12

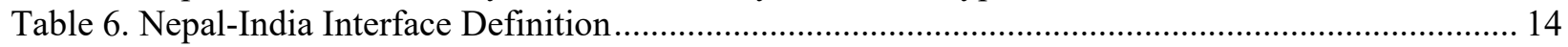

Table 7. Optimization Parameters and Units in Combined India and Nepal "South Asia" Model............. 15

Table 8. Key Assumptions in the Base-BAU and High Build-BAU Scenarios ...................................... 16

Table 9. Electricity Production Costs in the Base-BAU and High Build-BAU Scenarios (USD millions)

Table 10. Hours of Congestion on Transmission between Nepal and India Base and High Build Scenario

Table 11. Scenarios Examined, Coordinated Operations...................................................................... 22

Table 12. Electricity Production Costs in the Coordinated Operations Scenarios, and Difference from

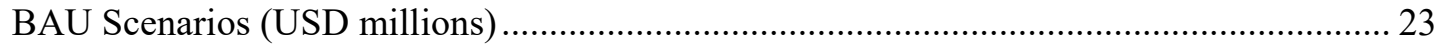

Table 13. Transmission Congestion between Nepal and Neighboring Indian States, All Scenarios.......... 27

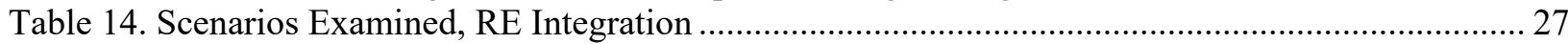

Table 15. Net Flows between Nepal and Indian States with Different Renewable Energy Levels in India

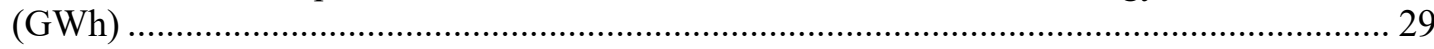

Table 16. Scenarios Examined, Bangladesh, BAU, and Coordinated Operations ..................................... 31

Table 17. Effect of Increased Generation to Serve Bangladesh on Total Production Costs (USD millions)

Table 18. Transmission Congestion between Nepal and Neighboring Indian States, High Build-CO

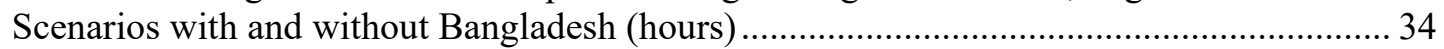

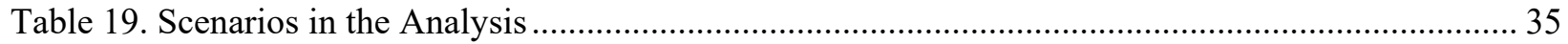

Table 20. Generation and Production Cost Differences between ISO Scenarios .................................... 35

Table 21. Transmission Congestion between Nepal and Neighboring Indian States, All Scenarios (hours) 


\section{Introduction}

Recent developments on both sides of the border between India and Nepal highlight new opportunities for increased cross-border energy trade (CBET). First, both countries anticipate continued strong growth in electricy demand. As demand grows, CBET can promote coordinated use of energy resources and potentially reduce the need for investments in new infrastructure. Second, Nepal's power system planners anticipate significant growth in the country's hydroelectric generating capacity. Power trade with India provides hydropower developers an opportunity to increase return on investments through export sales while also giving neighboring states in India access to low-cost hydropower. Third, falling technology costs and national energy policies have led to significant growth in renewable energy (RE) investments in India, with much more expected in the coming years. Coordinated regional trade can facilitate RE integration by increasing access to resources available for balancing. This study explores potential CBET from an operations perspective among India, Nepal, Bangladesh, and Bhutan by examining the technical and economic impacts of trade on both systems in the year 2022 .

\subsection{Background}

India has an installed generation capacity of 331 gigawatts $(\mathrm{GW})$, with coal and renewable energy sources accounting for $193 \mathrm{GW}(58 \%)$ and $63 \mathrm{GW}(19 \%)$, respectively, and a peak demand of $164 \mathrm{GW}$ (CEA 2017a). The Government of India has set a target of $175 \mathrm{GW}$ of RE by 2022, including $100 \mathrm{GW}$ of solar and $60 \mathrm{GW}$ of wind. India anticipates its electricity demand to grow $5.9 \%$ annually over the next decade, with peak demand reaching $230 \mathrm{GW}$ by 2022 (CEA 2017b). Furthermore, in 2016 the Government of India Ministry of Power released updated guidelines on CBET that allows for trading of power through the Indian Power Exchanges under certain conditions. $^{2}$

Nepal's power system differs significantly from that of India in both size and composition. The installed capacity is 968 megawatts (MW) and almost exclusively hydropower, with two thermal plants accounting for 6\% of installed capacity (NEA 2017). A major earthquake in 2015 damaged several existing hydropower plants and delayed construction on others, resulting in persistent load shedding for consumers and increased reliance on imports from India. Imports from India accounted for 35\% of annual consumption in the 2016-2017 operating year. Investments in new plants and repairs to damaged infrastructure have gradually improved electricity supply in Nepal and, in the last year, major urban centers experienced their first 24hour periods without load shedding since the earthquake. Continued development of $3.8 \mathrm{GW}$ of planned hydropower projects could eliminate the remaining load shedding in the coming years and shift the trade balance between Nepal and its neighbors, allowing Nepal to become a net exporter. Electricity demand in Nepal is projected to grow by $7.2 \%$ annually, increasing from 4 gigawatt hours (GWh) in 2016 to $10 \mathrm{GWh}$ in 2022 (WECS 2017).

The Nepalese and Indian power systems are already connected by multiple cross-border transmission lines and there are plans to further integrate the two systems with new 400-kilovolt $(\mathrm{kV})$ transmission connections. Previous studies have investigated potential impacts of specific cross-border projects (ADB 2015) and coordinated long-term planning (WB 2015; SARI/EI

\footnotetext{
${ }^{2}$ https://powermin.nic.in/sites/default/files/webform/notices/Guidelines\%20for\%20Cross\%20Boarder\%20Trade.pdf
} 
2017) between India and Nepal. The Asian Development Bank assessed the potential benefits of a single $400-\mathrm{kV}$ transmission line using power flow models under different scenarios of hydropower development in Nepal and found the benefits of the line could far exceed its costs in all scenarios due to reduced costs of operations and unserved energy. Looking beyond a single project, capacity expansion modeling by the World Bank found that coordinated planning and unrestricted trade among seven South Asian countries could save U.S. \$226 billion, or U.S. \$7 billion annually. The SARI/EI study connected power system planning with a larger energy sector model to assess the broader economic impacts of increased CBET between India and Nepal. The study finds increased CBET results in increased hydropower development and household electricity consumption in Nepal but impacts in India are negligible given its larger economy and power system.

\subsection{Study Approach}

This study aims to advance the discussion surrounding CBET between India and Nepal through the unique contribution of a detailed simulation of system operations of the South Asia region. The study is supported by the U.S. Department of State's Bureau of South and Central Asian Affairs Regional Connectivity Program.

Our primary tool is a production cost model, which simulates optimal unit commitment and dispatch of the system subject to physical, operational, and market constraints. There are two main benefits to modeling a full chronological time series of system operations. First, in systems with high levels of variable RE, production cost models can capture hour-to-hour variability in load and RE generation. This modeling capability is increasingly important as wind and solar generation grow in India. Second, production cost models can capture potential opportunities for trade and greater utilization of the most efficient generating units that arise when peak demand occurs at different times in different areas. The detailed production cost model captures the flexibility requirements necessary to balance generation and demand every hour of the year and the cost associated with those operational decisions. This study is the first attempt to examine CBET over a full year of system operations and with detailed representations of the generation and transmission systems of each country.

This study builds on a detailed production cost model of the Indian power system developed under the Greening the Grid program, an initiative co-led by India's Ministry of Power and U.S. Agency for International Development to support the iniatives taken by India's Ministry of Power for large-scale integration of RE. The model was developed by a collaborative modeling group from India's Power System Operation Corporation, Limited (POSOCO), National Renewable Energy Laboratory (NREL), and Lawrence Berkeley National Laboratory, with additional input from a wide range of experts from across the Indian power sector. Its initial use was for an analysis of the operational impacts of $175 \mathrm{GW}$ of variable RE on the Indian power system in 2022 (Palchak et al. 2017).

Analysis of CBET required building a Nepal model to be added to the India model. The Nepal model was developed by NREL based on data and guidance from engineers at Nepal Electricity Authority (NEA). 


\subsection{Structure of the Report}

Section 2 presents the study scenarios and methods used to create the production cost model and input databases. The model results are presented in Section 3. Finally, Section 4 summarizes the findings and presents final conclusions. 


\section{Study Scenarios, Modeling Methodology, and Assumptions}

The objective of this study is to provide an empirical foundation for identifying the opportunities and associated characteristics and value of CBET across Nepal, India, Bangladesh, and Bhutan, with a primary focus on trade between Nepal and India. To meet this objective, we use a detailed model of the Nepal and India power systems combined with a simplified representation of Bhutan and Bangladesh to simulate a year of system operations at one-hour resolution. ${ }^{3}$ The test year is 2022 .

Because project development and institutional changes could affect CBET opportunities, the study evaluates results under several scenarios. The following sections describe the study scenarios, the model setup and execution, and data sources. This section also presents assumptions for the South Asian power system and explains the countries' integration into a single combined model.

\subsection{Study Scenarios}

The study analyzes nine scenarios constructed by varying four parameters:

- The amount of hydro capacity that will exist in Nepal in 2022

- Hurdle rates on certain transmission corridors ${ }^{4}$

- The amount of wind and solar capacity that will exist in India in 2022

- Bangladesh power supply contract with Nepal.

Table 1 outlines the parameter configurations used in each scenario. The remainder of this section describes each parameter's variation.

\subsubsection{Hydro Buildout}

Hydro capacity is set to either Base (2,840 MW) or High (4,552 MW) in each scenario. These two numbers represent a plausible range of the hydroelectric capacity likely to be operational in Nepal by 2022. Section 2.3 describes the process of determining the set of generators modeled in each case. Juxtaposing results from these two scenarios will help determine the extent to which CBET is sensitive to the amount of hydro built in Nepal.

\footnotetext{
${ }^{3}$ Representation of Bhutan was simplified for lack of quality data and represents only a fraction of the potential hydro generation that is likely to be available to the region in the future. This could impact the results, however the total generation is small compared to the capacity and energy needs of the region and would likely have marginal impact to the scenarios analyzed.

${ }^{4}$ Hurdle rates are not a cost and do not add directly to the production cost. However, they do create price differentials between adjacent parts of the grid that affect the scheduling and dispatch of generators, and therefore indirectly affect the total cost. The rates are measured in Indian rupee (INR) per unit of energy transferred.
} 
Table 1. Study Scenarios

\begin{tabular}{lcccc}
\hline \multicolumn{1}{c}{ Scenario Name } & $\begin{array}{c}\text { Hydro } \\
\text { Buildout }\end{array}$ & Hurdle Rates & $\begin{array}{c}\text { India Wind } \\
\text { and Solar } \\
\text { Capacity }\end{array}$ & Bangladesh \\
\hline Base-BAU & Base & Business as usual (BAU) & $160 \mathrm{GW}$ & Not included \\
High Build-BAU & High & BAU & $160 \mathrm{GW}$ & Not included \\
Base-CO & Base & Coordinated Operations (CO) & $160 \mathrm{GW}$ & Not included \\
High Build - CO & High & CO & $160 \mathrm{GW}$ & Not included \\
High Build - BAU - Low RE & High & BAU & $70 \mathrm{GW}$ & Not included \\
High Build - CO - Low RE & High & CO & $70 \mathrm{GW}$ & Not included \\
Bangladesh-CO & High & CO & $160 \mathrm{GW}$ & Included \\
Bangladesh-BAU & High & BAU & $160 \mathrm{GW}$ & Included \\
BBIN Independent System & High & None within ISO & $160 \mathrm{GW}$ & Included \\
Operator (ISO) & & & & \\
\hline
\end{tabular}

\subsubsection{Hurdle Rates}

Hurdle rates are a modeling technique to encompass all non-physical barriers to transmission utilization such as differences in scheduling practices that could impede trade. The hurdle rate represents a price differential that needs to be exceeded in order for trade to occur between two nodes. Previous modeling of the Indian power system suggests that the price differential for interstate trade is around INR 1,000/megawatt hour (MWh) (Palchak et al. 2017). We maintain this Indian interstate hurdle rate in this study.

In addition to the Indian interstate hurdle rate, we add location- and season-specific hurdle rates between Nepal and India to form the business as usual (BAU) scenario (Table 2). The hurdle rates between Nepal and bordering Indian states reflect existing economic barriers to CBET between the two countries. To proxy economic restrictions on the flow of power from India to Nepal, we use the current contract prices paid by NEA for imported power. These prices tend to be higher than energy prices on the day-ahead spot markets operated by the Indian Energy Exchange. The effect of using these hurdle rates is that the model does not move power across the border to Nepal unless the marginal cost of energy in Nepal exceeds the marginal cost of energy in Bihar or Uttar Pradesh or Uttarakhand by the amount of the hurdle rate. Only then does power flow from India to Nepal. 
Table 2. Hurdle Rates Associated with Different Scenarios

\begin{tabular}{|c|c|c|}
\hline Direction & $\begin{array}{c}\text { Dry Season } \\
\text { (December-May) }\end{array}$ & $\begin{array}{c}\text { Wet Season } \\
\text { (June-November) }\end{array}$ \\
\hline & \multicolumn{2}{|c|}{ BAU Scenario } \\
\hline Nepal $\rightarrow$ India & INR 6,500 / MWh & INR 3,000 / MWh \\
\hline Bihar $\rightarrow$ Nepal & \multicolumn{2}{|c|}{ INR 3,500 / MWh } \\
\hline Uttar Pradesh $\rightarrow$ Nepal & \multicolumn{2}{|c|}{ INR 6,500 / MWh } \\
\hline Uttarakhand $\rightarrow$ Nepal & \multicolumn{2}{|c|}{ INR 6,500 / MWh } \\
\hline & \multicolumn{2}{|c|}{ Coordinated Operations Scenario } \\
\hline India $\leftarrow \rightarrow$ Nepal (net export charge) * & \multicolumn{2}{|c|}{ INR 1,000 / MWh } \\
\hline & \multicolumn{2}{|c|}{ BBIN ISO Scenario } \\
\hline $\begin{array}{l}\text { Within Bhutan, Bangladesh, India's Eastern } \\
\text { region, and Nepal }\end{array}$ & \multicolumn{2}{|c|}{ INR 0 / MWh } \\
\hline
\end{tabular}

*This is the same hurdle rate applied to transactions between Indian states. At INR 65 to 1 U.S. dollar (USD) exchange, INR 6,500 = USD 100; INR 3,000 = USD 46; INR 3,500 = USD 54; INR 1,000 = USD 15

To represent BAU constraints on flows in the other direction, from Nepal to India, we use the prices at which NEA buys peaking run-of-river hydro generation from independent power producers (IPPs). This comports anecdotally with statements made by IPPs in interviews with NREL about the value of exporting their output to India. NEA pays about INR 6,500/MWh for peaking run-of-river (RoR) in the dry season and INR 3,000/MWh for all categories of hydro generation in the wet season. In addition, Nepal's Ministry of Energy directed NEA to include "take or pay" provisions in new purchase contracts with IPPs, meaning that for a specified quantity of production, NEA will pay even if it does not take delivery of the energy. Thus the fixed domestic purchase prices are essentially a "price to beat" for exporting Nepal hydro to India, in that the value to Bihar, Uttar Pradesh, or Uttarakhand has to be higher than what the IPP would forego by not selling its power to NEA. As detailed in the companion report to this study (Hurlbut, 2018), IPPs could provide nearly half of Nepal's power supply by 2020. Moreover, NEA would likely reserve the use of its own hydro resources to follow domestic load and otherwise maintain reliability on its own grid. All of this suggests that domestic IPP tariff prices are a reasonable starting point for representing BAU on exporting hydro from Nepal to India.

While this approach results in relatively high hurdle rates, it still does not specifically include other factors such as domestic transmission limitations that could indirectly restrict hydro exports to India. The purpose of using hurdle rates is not to precisely value institutional limitations, however. Rather, it is to provide a reasonable basis for comparing one scenario with another by postulating a material change in institutional arrangements.

The Coordinated Operations (CO) scenario removes the charges derived from hydro tariffs and applies only the INR 1,000/MWh hurdle rate between Nepal and India. In other words, this scenario assumes that CBET between India and Nepal has the same market friction that exists between Indian states. A third scenario, BBIN ISO, has no hurdle rates on flows inside the combined territory of Nepal, Bhutan, Bangladesh and India's Eastern region (BBIN), while the rest of India maintains the standard interstate hurdle rate. This framework represents full 
coordination for commitment and dispatch among India's Eastern region and its neighboring countries. This scenario is particularly relevant to the transfer of hydropower from Nepal to Bangladesh, in that it provides a benchmark based on the maximum achievable degree of operational coordination. (See the sidebar for examples of increasing coordination between neighboring regions.)

\section{"Coordinated operations" in practice}

Operational coordination can encompass many practices, of which neighboring balancing authorities (i.e., system operators for each grid) might adopt several, few, or none. Therefore, coordination is not a simple binary condition. The INR 1,000/MWh hurdle rate used in the CO scenarios assumes some combination of practices that reduce some, but not all, of the transaction costs involved in moving power from one jurisdiction to another. Here we list a few examples of coordination ranging from low effort to high effort.

- Tariff reciprocity. Energy exchanges are charged the same regardless of which direction they flow.

- Sharing area control error (ACE). ACE is the instantaneous difference between a balancing area's net actual and scheduled interchange, i.e., a metric of a system operator's ability to maintain balance according to schedule. Combining ACE across neighboring grids will usually produce a single ACE that is smaller and more easily corrected. Consolidating reserves and access to least-cost resources can result in additional savings.

- Shared area imbalances. An energy imbalance is similar to instantaneous ACE, but refers to how the operator schedules generators, imports, and exports against day-ahead forecasts or shortly before real-time delivery of electricity. As with sharing ACE, sharing imbalances tends to produce a smaller imbalance that is easier and cheaper to address from the combined least-cost resources of both grids.

- Common scheduling and unit commitment practices. Using the same standards for communications between each control area and the generators it schedules makes joint response to ACE and imbalances operationally seamless. This coordination also includes using common timelines for day-ahead schedule submissions and unit commitment and adjustments to real-time schedules.

- Energy imbalance market (EIM). An EIM is a formal market for balancing energy simultaneously across all participating control areas through a sequence of regular auctions. Often an EIM includes an hourly day-ahead component and a real-time or same-day component for each five- or fifteen-minute interval.

- Independent system operator (ISO). An ISO is an independent market and system operator that would merge two or more balancing authorities into a single operational entity responsible for maintaining balance. The ISO allocates transmission rights based on a system of bids and offers and optimizes unit commitment and dispatch decisions to minimize system costs. Depending on design, each participating control area may schedule its load and resources internally, but it then must transmit its schedule to the ISO. All energy balancing and ancillary services are under the ISO's control.

For more details, see "Balancing Area Coordination: Efficiently Integrating Renewable Energy into the Grid" https://www.nrel.gov/docs/fy15osti/63037.pdf. 


\subsubsection{India Wind and Solar Capacity}

India wind and solar capacity in Table 1 refers to India's 2022 installed wind and solar capacity. It is set to either $70 \mathrm{GW}$ or $160 \mathrm{GW}$, corresponding to the intermediate and target RE scenarios modeled in Palchak et al. 2017. ${ }^{5}$ The purpose of comparing the two RE capacity configurations is to test whether Nepal's hydro can affect the operations of India's grid with $160 \mathrm{GW}$ of wind and solar capacity.

\subsubsection{Bangladesh}

Bangladesh's power grid is not synchronized with the rest of South Asia. Instead, it connects to the Indian states of West Bengal and Tripura via a direct current (DC) tie and radial line, which supply Bangladesh with 1,000 MW and 100 MW, respectively (JTT 2016; PT 2018). As a scenario, we model a contract where Nepal continuously supplies Bangladesh with 1,000 MW through the DC interconnection with West Bengal (we do not represent the radial connection with Tripura). The purpose is to analyze, at varying levels of coordination, what might happen to the flow of hydropower from Nepal if there were an additional 1,000 MW obligation to serve Bangladesh: whether there might be additional flows from Nepal, or whether the same volume from Nepal would be reallocated contractually from India to Bangladesh.

\subsection{Model Setup and Execution}

To simulate power system operations, we use a unit commitment and economic dispatch (UC\&ED) model. The model balances supply and demand in every hour of the 2022 simulation year, subject to physical and operator-imposed constraints. By simulating UC\&ED in every onehour period of 2022, the study provides a full chronological picture of the year's operations. The results capture intertemporal constraints that affect operator decisions, such as RE availability, generator minimum up and down times, ramp rates, and maximum energy limits for hydropower plants.

The UC\&ED simulation relies on the commercially available mixed integer linear programming software PLEXOS Integrated Energy Model, developed by Energy Exemplar and configured here to use the XPRESS-MP solver. The software commits and dispatches generators to meet load at least-cost, while adhering to thousands of physical constraints, including transmission limits, generator parameters, and limits on water availability for hydropower generation. Transmission flows are calculated with a linearized DC optimal power flow approximation. The India-Nepal PLEXOS model has been configured to structure the mixed-integer optimization as three phases: (1) a single year-long step to plan scheduled outages, (2) a second year-long step to optimally translate multi-day hydro constraints into target end-of-day reservoir volumes, and (3) 365 one-day optimization steps with one-hour resolution to schedule and dispatch the remaining generation to meet load. ${ }^{6}$

Although the UC\&ED simulation captures the constrained cost-minimization problem at the heart of power system operations, it relies on a few key simplifying assumptions. The model does not include load and renewable energy forecast errors and does not account for units that may be committed for reliability or contractual obligations. This analysis aims to assess the

\footnotetext{
${ }^{5}$ As of April 30, 2018, the installed wind and solar capacity in India was 55.7 GW (CEA 2018)

${ }^{6}$ To emulate the decisions made in an operations room, which would weigh known changes to load or other factors beyond a single day, each one-day step solves for 48 hours and then discards the last 24 hours.
} 
impacts of cross-border trade that are economically efficient and technically feasible on an already built system. As such, the UC\&ED dispatch model does not optimize investment decisions or account for fixed costs. It also assumes UC\&ED decisions between India and Nepal are coordinated apart from the transmission hurdle rates described above.

\subsection{Data Sources and Assumptions}

This study uses the India power system database developed for Greening the Grid, which simulates the operation of the Indian power system in 2022 with $175 \mathrm{GW}$ of RE (Palchak et al. 2017). This database was developed and validated in collaboration with experts from across the Indian power sector. Details of data sources and assumptions for load, generation, and transmission are provided in Section 2 of that report.

The Nepal power system database is based on data and guidance provided by NEA. Starting with transmission network data, we overlaid 2022 hydro generator locations, applied water availability constraints for hydropower plants, and derived a 2022 load profile, as described in the following sections.

\subsubsection{Transmission}

Transmission network data in the 2022 Nepal UC\&ED model is derived from two 2022 PSS/E ${ }^{7}$ files supplied by NEA. Table 3 summarizes the number of transmission lines and nodes (substations) included in the 2022 model. Section 2.4 details the cross-border lines connecting Nepal and India.

Table 3. Basic Information on the Modeled 2022 Nepal Transmission Network

\begin{tabular}{lcc}
\hline Voltage & Number of Lines & Number of Nodes \\
\hline 400 kilovolts & 26 & 15 \\
220 kilovolts & 29 & 21 \\
132 kilovolts & 141 & 93 \\
66 kilovolts & 27 & 20 \\
33 kilovolts & - & 20 \\
\hline
\end{tabular}

\subsubsection{Hydro Capacity}

The uncertain status of many proposed and ongoing hydroelectric construction projects makes forecasting Nepal's 2022 installed hydro capacity difficult. NEA's 2022 PSS/E file gives network locations for 7,442 MW of hydro capacity — an upper bound on what could exist in that year. From this list of plants, we identified 2,891 MW of capacity to exclude from the model because it was either located inside India, terminated, not anticipated to be operational by 2022, identified by NEA for exclusion, or not locatable. The capacity remaining after these exclusions - 4,551 MW-defines the High Build scenario. For the Base buildout scenario, we further excluded proposed projects that had not reached financial closure according to NEA 2017 and projects that we were not able to identify as likely candidates within our study year

\footnotetext{
${ }^{7} \mathrm{PSS} / \mathrm{E}$ is a transmission system planning software package developed by Siemens PTI.
} 
timeframe. These exclusions totaled 1,712 MW, leaving 2,839 MW of installed capacity in the Base buildout scenario.

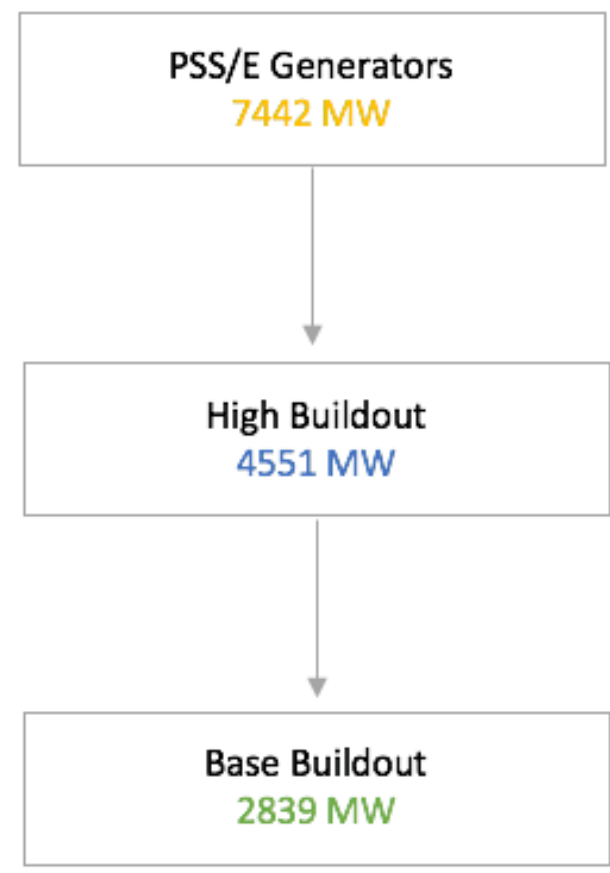

\section{Exclusions}

- Inside India (442 MW)

- Complete after 2022 (2229 MW)

- Terminated (26 MW)

- NEA feedback (180 MW)

- Projects with unknown location (14 MW)

- Proposed without financial closure (429 MW)

- Unidentified projects (1283 MW)

Figure 1. Methodology for determining Nepal's 2022 hydro generation capacity

NEA operates two thermal generators (Hetauda Diesel and Duhabi Multifuel) which together account for $1.6 \%$ and $1.0 \%$ of its installed capacity in the Base and High Build scenarios. Estimated variable cost information and other operational parameters for the two plants come from Palchak et al. 2017. No growth in wind or solar generation is assumed for Nepal.

\subsubsection{Hydro Constraints}

Representing hydro generation in a UC\&ED model is inherently difficult for a number of reasons, including:

- Hydro plant operations must consider multiple time scales of minutes and hours and also how much water should be stored for future use over several weeks and months

- Available capacity is subject to seasonal and inter-annual changes that are exogenous to power system operations, such as rainfall and inflows, as well as losses due to evaporation, silting, and seepage

- Water use for electricity generation competes with water demand for other uses such as irrigation and recreation

- Operational planning for plants on the same river must consider interdependencies between upstream and downstream plants.

The 2022 Nepal database consists of 173 hydropower plants (in the High Build scenario), most of which are small RoR plants located on one of the tributaries that feed Nepal's two main river basins. The generation from each plant is characterized based on its location within Nepal and head storage capacity. The key instrument in formulating Nepal's 2022 hydro constraints is a log 
of 19 months of historic plant-wise hydro generation from April 2016 to November 2017 (1 Baisakh 2073 to 31 Kartik 2074) provided by NEA. ${ }^{8}$ Using the historical generation data, it is possible to derive average monthly capacity factors by major river basin as presented in Figure $2 .{ }^{9}$

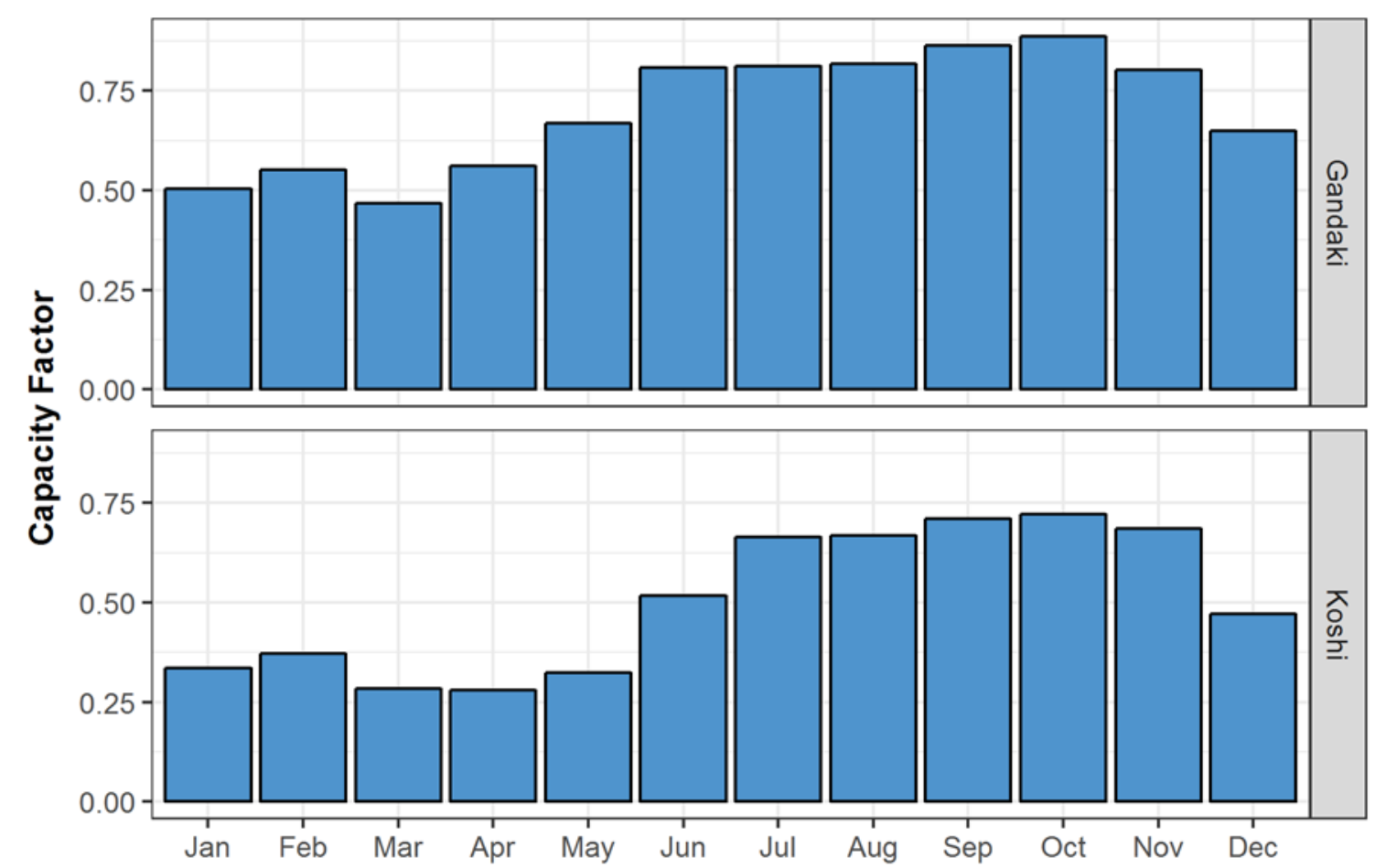

Figure 2. Average monthly capacity factor by major Nepalese river basin, capacity weighted

Having categorized the generation fleet by river basin, a further categorization by storage capacity results in six generator types: two river basins (Koshi, Gandaki) crossed with three generator types (run-of-river, peaking run-of-river, and storage). In total, there are 165 run-ofriver plants, six peaking run-of-river plants, and two storage plants in the High Build scenario.

Table 4 lists capacity by generator type in the Base and High Build scenarios and Table 5 indicates the constraints applied to each generator type.

Table 4. Nepal 2022 Database Hydro Capacity by Generator Type, Base/High Build Scenario (MW)

\begin{tabular}{lccc}
\hline & Run-of-River & Peaking Run-of-River & Storage \\
\hline Koshi & $900 / 1494$ & $456 / 456$ & $60 / 60$ \\
Gandaki & $965 / 2082$ & $339 / 339$ & $120 / 120$ \\
\hline
\end{tabular}

\footnotetext{
${ }^{8}$ Nepal uses the Vikram Samvat calendar, which begins mid-April, rather than the Gregorian calendar.

${ }^{9}$ Nepal's three major river basins are the Koshi, Gandaki, and Karnali, which roughly cover the eastern, central, and western thirds of the country, respectively. Because of a low sample size, generators in the Karnali river basin are considered part of Gandaki. The minority of generators located outside of the three major river basins are then allocated to either Koshi or Gandaki.
} 
Table 5. Nepal 2022 Database Hydro Constraints by Generator Type

\begin{tabular}{l|c|c|c}
\hline & Run-of-River & Peaking Run-of-River & Storage \\
\hline Inflow Source & Historic basin-specific average monthly capacity factors \\
\hline Inflow Units & $\mathrm{MW}$ & Cumec & Cumec \\
\hline Inflow Scalar & Unit installed capacity & Unit installed capacity & $\begin{array}{c}\text { Unit annual } \\
\text { designed generation }\end{array}$ \\
\hline Storage Capacity & 0 hours & $4.6-6.4$ hours & 336 hours \\
\hline
\end{tabular}

Run-of-river generators must maintain the basin-specific average monthly capacity factors in Figure 2 for every hour of the given month. They have no head storage and therefore must spill any water that cannot be used in the interval in which it arrives.

Peaking run-of-river generators benefit from approximately six hours of head storage (i.e., 60 $\mathrm{MWh}$ for a $10 \mathrm{MW}$ generator) which allows them to optimize generation according to intraday demand, but not long-term variations in demand. Whenever possible, we use publicly available data (NEA 2018a) on storage volumes and cumec (cubic meters per second)-to-MW conversion efficiencies to determine peaking run-of-river parameters (accounting for the range of storage capacity shown in Table 5). For generators without data we assume exactly six hours of storage.

Nepal currently has one operational hydro storage generator (Kulekhani I) and one under construction (Tanahu Hydropower Project). Data inputs for each plant come from publicly available documents by the plant developers (NEA 2018b; THL 2018). We use data for reservoir storage volume and assume cumec-to-MW conversion efficiencies for both plants such that the reservoirs can supply two weeks of energy when operating at max capacity (i.e., $3.36 \mathrm{GWh}$ for a $10 \mathrm{MW}$ plant). To account for silting, evaporation, irrigation needs, and other constraints that could cause storage generator capacity factors to deviate from the basin-wide average, we scale each storage natural inflow profile by its annual designed generation: $211 \mathrm{GWh}$ for Kulekhani I and 585.7 GWh for Tanahu. An additional constraint requires Kulekhani II, a run-of-river generator directly downstream from Kulekhani I, to generate in proportion to Kulekhani I's water release.

\subsubsection{Load}

Nepal's 2022 load profile is derived from the same historic plant-wise hydro generation data as the hydro constraints. The data provided by NEA includes imports and load shedding in addition to domestic generation. By summing imports, load shedding, and domestic generation, we obtained a time series of potential domestic load for April 2016 to November 2017.

NEA's load shedding data quantifies the maximum power deliverable to a disconnected customer. It does not necessarily indicate the power that the customer would have consumed if connected. Unmodified, the discrepancy would cause load shedding - and thereby load - to be overestimated, particularly during peak periods. To approximate disconnected customer demand rather than maximum potential demand, we smoothed all load shedding values in excess of the monthly mean according to the following formula, 


$$
L_{m, t}^{*}=\bar{L}_{m}+\left(L_{m, t}-\bar{L}_{m}\right)^{9 / 10}
$$

where,

$$
\begin{aligned}
& L_{m, t}^{*} \text { is the revised load shedding value in month } m \text { at time } t \\
& \bar{L}_{m} \text { is the average load shedding in month } m \text {. } \\
& L_{m, t} \text { is the original load shedding value in month } m \text { at time } t
\end{aligned}
$$

This formula was arrived at through a heuristic technique to create daily load profiles that tempered the extreme daily load factor (i.e., the difference between the daily valley and peak demand) found in the NEA load shedding data to realistic levels.

The NEA load data starts in April 2016 and ends in November 2017. To arrive at a complete Gregorian calendar year of load data, we scaled the data from November 17, 2016 to December 31,2016 by 1.087 , Nepal's average annual peak load growth since 2000 , to represent the end of 2017.

The Nepal Water and Energy Commission Secretariat's 2014-2040 load forecast (WECS 2017) estimates total annual demand in 2022 will reach 10.3 terawatt hours (TWh). To create the 2022 load profile while preserving the hourly load shape from 2017, we scaled all values such that total annual demand matches the national forecast. Based on this scaling, the 2022 peak demand is expected to reach 1,839 MW.

\subsection{Integrating the South Asia Models}

The independently developed India and Nepal power system databases require careful integration to function as a single model. The following sections address the challenges of linking the models with cross-border alternating current (AC) ties and reconciling their model parameters.

\subsubsection{Nepal-India Interface}

Table 6 and Figure 3 show parameters and locations for the six transmission corridors at or above voltages of $132 \mathrm{kV}$ expected to connect Nepal and India in 2022. The model ignores transmission between India and Nepal below $132 \mathrm{kV}$. Parameters for the six corridors come from a variety of sources including NEA's PSS/E file, POWERGRID, CEA, and generic transmission line parameters (NEA 2017; Palchak et al 2017; MEA 2014; Shrestha 2016; ANI 2018). We assume the Nepalese and Indian grids will be fully synchronous by 2022. 
Table 6. Nepal-India Interface Definition

\begin{tabular}{llcccc}
\hline $\begin{array}{l}\text { Nepal } \\
\text { Substation }\end{array}$ & $\begin{array}{l}\text { India } \\
\text { Substation }\end{array}$ & Voltage (kV) & Circuit & Conductor Type & $\begin{array}{c}\text { Max Flow I } \\
\text { Circuit (MW) }\end{array}$ \\
\hline Dhalkebar & Muzaffarpur & 400 & Double & Twin moose & 552 \\
New Butwal & Gorakhpur & 400 & Double & Quad moose & 1,105 \\
Kushaha & Kattaiya & 132 & Double & Panther & 84 \\
Parwanipur & Raxaul & 132 & Single & Panther & 84 \\
Gandak & Ramnagar & 132 & Single & Panther & 84 \\
Mahendranagar & Tanakpur & 132 & Single & Panther & 84 \\
\hline
\end{tabular}

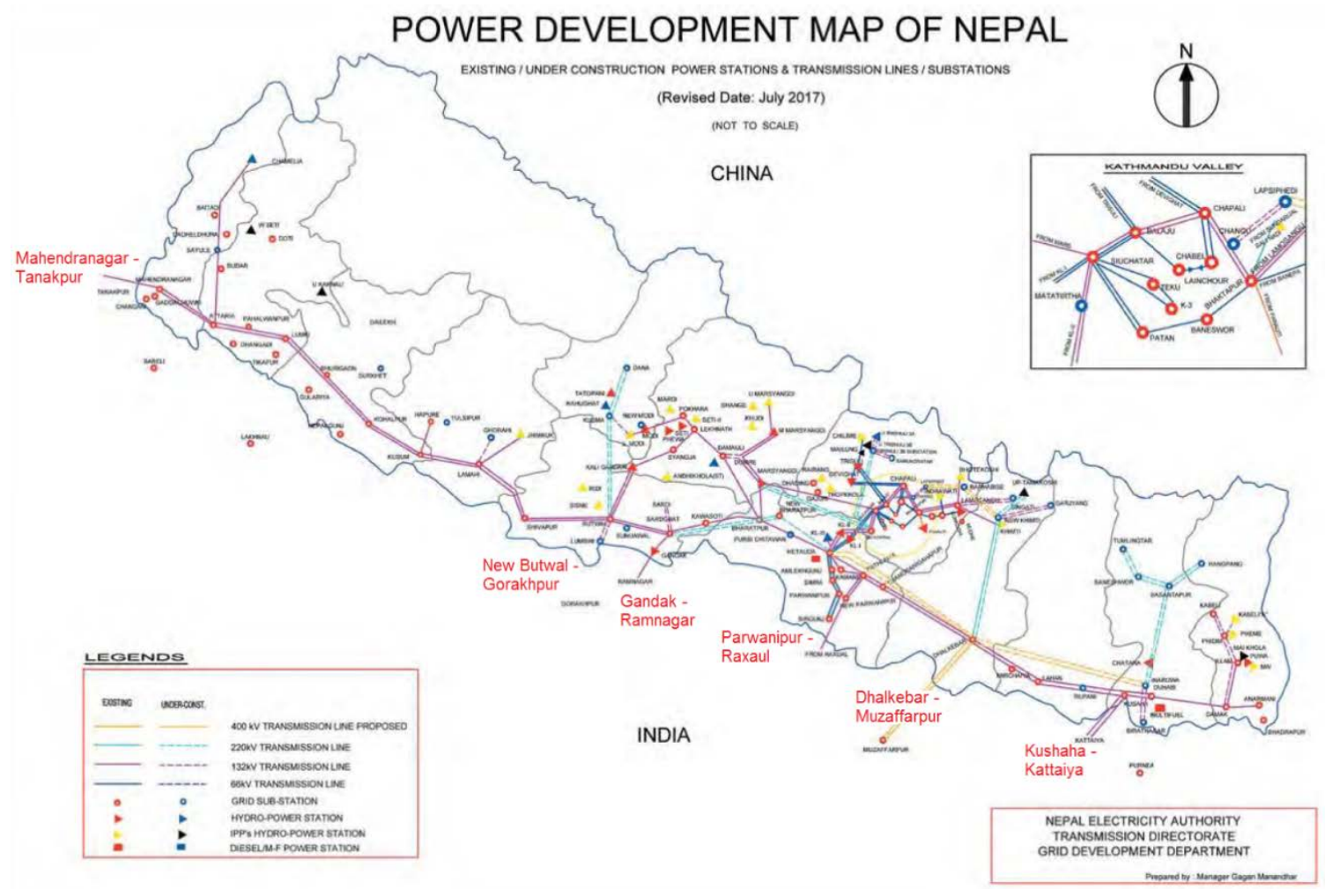

Figure 3. Nepal-India interface illustration.

Adapted from NEA 2017.

While transmission representation inside Nepal is at the substation level (nodal representation), transmission inside India is aggregated by state. The assumption is that India's intrastate congestion is resolved endogenously and does not affect interstate flows, which greatly simplifies the UC\&ED formulation. Preserving Nepal's substation-level representation allows for an analysis of how each scenario impacts power flows inside Nepal and between Nepal and Indian states. 


\subsubsection{Model Parameters and Other Constraints}

Various optimization parameters and physical units must be standardized between the India and Nepal power system databases as a final step towards their integration into a combined South Asia model. Table 7 gives the optimization parameters used in the combined UC\&ED simulation. The USD operating costs of Nepal's two thermal generators are converted to INR at INR $65=1$ USD, while Nepal's zero marginal cost hydro generation requires no currency conversion.

Table 7. Optimization Parameters and Units in Combined India and Nepal "South Asia" Model

\begin{tabular}{lc}
\hline Parameter / Unit & Value \\
\hline Currency & INR \\
Value of lost load & INR 1 crore \\
Value of reserve shortage & INR 0.4 crore \\
\hline
\end{tabular}

The India model holds operating reserves at the regional level as in Palchak et al. 2017, which are equal to the capacity of the largest unit in the region plus $50 \%$ of the summed capacity of the largest unit in each state in the region. The Nepal region holds no operating reserves in the model. ${ }^{10}$

\subsubsection{Bhutan and Bangladesh}

The India database in Palchak et al. 2017 includes select data of the Bhutan power system necessary to capture power exports from Bhutan to India. Bhutan is a net exporter and, as such, the database does not include information on Bhutan's load or the entire generation and transmission system. Transmission in Bhutan is represented by a single node with 19 crossborder lines between Bhutan and the Indian states of Assam and West Bengal. The database includes $60 \mathrm{MW}$ of run-of-river that are involed in CBET. Monthly hydro availability in Bhutan is based on 2014 supervisory control and data acquisition (SCADA) data provided by POSOCO.

For the Bangladesh scenario, we model only the increased demand that could come with a direct purchase of power from Nepal. We represent this as an additional 1,000 MW of constant demand at the Baharampur DC tie in West Bengal.

Future work could include detailed modeling of the Bhutan and Bangladesh power systems to examine the impact of CBET on these systems in greater detail.

\footnotetext{
${ }^{10}$ Nepal does hold operating reserves in reality, however optimal dispatch for energy in the model results in many periods where there is unrequisitioned capacity that could be used for reserves, and therefore the assumption of zero reserve provision is likely negligible on the results.
} 


\section{Production Cost Modeling Results}

The scenarios and results described in this section aim to inform the following questions.

- If Nepal's hydropower capacity grew and nothing else changed (i.e., no changes in coordination, no additional transmission expansion), what would the effect be on production costs in Nepal, production costs in India, and cross-border electricity trading?

- If reforms are put in place such that exchanges between Nepal and India are treated the same as exchanges between Indian states, how would an increase in Nepal's hydro capacity affect production costs in Nepal, production costs in India, and cross-border electricity trading?

- Would increased coordination between India and Nepal affect India's integration of wind and solar generation?

- How would coordination affect the wheeling of Nepal hydropower through India to Bangladesh?

- How would complete operational integration among India's Eastern Load Dispatch Center (LDC) area, Nepal, Bangladesh, and Bhutan affect generation costs and transmission congestion?

The results focus on the following outcomes:

- Changes in production costs for each area (including average cost per MWh generated)

- Changes in the types of generation dispatched

- Changes in transmission congestion between Nepal and India

- Changes in curtailment of energy from hydro, wind, and solar.

The results for India focus primarily on the areas adjacent to Nepal, represented by the Eastern and Northern LDC regions. Because CBET exchanges have less impact on the other regions of India, analyzing results on an all-India basis risks obscuring potentially significant sub-regional effects. One possible exception is how hydropower from Nepal might affect the integration of higher penetrations of wind and solar power across the subcontinent, which this analysis addresses on an all-India basis.

\subsection{Increased Nepal Hydropower with No Other Changes}

The Base-BAU and High Build-BAU scenarios provide a plausible range of the growth in Nepal's hydroelectric capacity that could occur by 2022. Contrasting results from these two scenarios provides a view of the effects on CBET if growth in Nepal's hydroelectric capacity is the only change - that is, if hydro capacity increases without any change in the level of coordination (represented by assumed hurdle rates) between India and Nepal. Table 8 summarizes the parameters used in each scenario.

Table 8. Key Assumptions in the Base-BAU and High Build-BAU Scenarios

\begin{tabular}{lcccc}
\hline Scenario & Hydro Buildout & Hurdle Rates & $\begin{array}{c}\text { India Wind and } \\
\text { Solar Capacity }\end{array}$ & Bangladesh \\
\hline Base - BAU & $2,839 \mathrm{MW}$ & BAU & $160 \mathrm{GW}$ & Not included \\
\cline { 1 - 2 } High Build - BAU & $4,551 \mathrm{MW}$ & & & \\
\hline
\end{tabular}




\subsubsection{Electricity Production Cost}

Generation from the additional 1,712 MW of hydro capacity in the High Build-BAU scenario translates into annual production cost savings of $0.3 \%$ or $\$ 106$ million across both countries. The production cost savings are the result of a $\$ 92$ million decrease in variable costs (fuel and operations and maintenance) and a reduction of $\$ 14$ million to the total costs of starting generators (Table 9). More than $80 \%$ of production cost savings accrue in India's Northern and Eastern regions, where hydro imports from Nepal displace coal.

Table 9. Electricity Production Costs in the Base-BAU and High Build-BAU Scenarios (USD millions)

\begin{tabular}{llcc}
\hline & Base-BAU & High Build-BAU & Difference from Base (\%) \\
\hline Eastern Region & $\$ 5,082$ & $\$ 5,016$ & $-\$ 66(-1.3 \%)$ \\
$\begin{array}{l}\text { Northern } \\
\text { Region }\end{array}$ & $\$ 8,170$ & $\$ 8,143$ & $-\$ 27(-0.3 \%)$ \\
Rest of India & $\$ 20,993$ & $\$ 20,979$ & $-\$ 14$ (negligible*) \\
India + Nepal & $\$ 34,245$ & $\$ 34,139$ & $-\$ 106(-0.3 \%)$ \\
\hline
\end{tabular}

${ }^{*}$ Change is less than $0.1 \%$.

Combined production cost savings accrue almost exclusively in India. Nepal's system is much smaller than India's, and its capacity consists of mostly zero-marginal-cost hydro generation (aside from two small thermal plants). Consequently, its production cost is well under $0.1 \%$ of India's in both scenarios.

Across India, the additional amount of hydropower from Nepal reduces the average cost of generation from \$20.99 per MWh to \$20.94 per MWh. Hydropower imports from Nepal tend to displace the most expensive generation sources. As a result, roughly $75 \%$ of the production cost reduction accrues because India generates less of its own electricity while roughly $25 \%$ accrues because the energy that India does generate is less expensive.

Locational marginal prices (LMPs), which are indicative of localized wholesale power prices under efficient market conditions, are primarily a function of three factors: the marginal cost of generation, transmission system losses, and transmission congestion. If there are no constraints on transmission flows (i.e., no congestion), LMPs everywhere will converge on one value that represents the marginal cost of generation systemwide. When congestion or hurdle rates constrain transmission flows, LMPs at the points with excess generation relative to demand will drop while LMPs at the nodes with excess electricity demand will increase. LMPs do not fully account for dispatch decisions because of the impact of hurdle rates. When the difference in LMPs between India and Nepal are less than the hurdle rate associated with moving power across the border, load is met by more costly resources on one side of the border, while lowercost resources on the other side remain unused. We assume no transmission losses.

In Figure 4 the LMP supply curves for Bihar and Uttar Pradesh are disaggregated into their seasonal components along with the hurdle rate for moving hydropower from Nepal to India. Nepal's marginal cost of hydropower generation is near zero, thus the hurdle rate of CBET makes up most of the cost of importing Nepal hydropower in India. Furthermore, prices in India 
tend to be inelastic with respect to the amount of hydropower imported from Nepal because total demand in India is large comparatively. The LMP in India, therefore, approximates the financial incentive for Nepal to export hydro generation; the hurdle rate represents the economic hurdle CBET must surmount. The intersection between the price duration curves and hurdle rate line approximates the proportion of periods in which hurdle rates, or lack of coordination, constrain flows from Nepal to India. CBET is hardly ever economic during the dry season, as evidenced by Nepal's lack of exports (discussed below and illustrated in Figure 8). During the wet season, imports from Nepal are economic roughly $65 \%$ of the time to Bihar and $55 \%$ of the time to Uttar Pradesh.
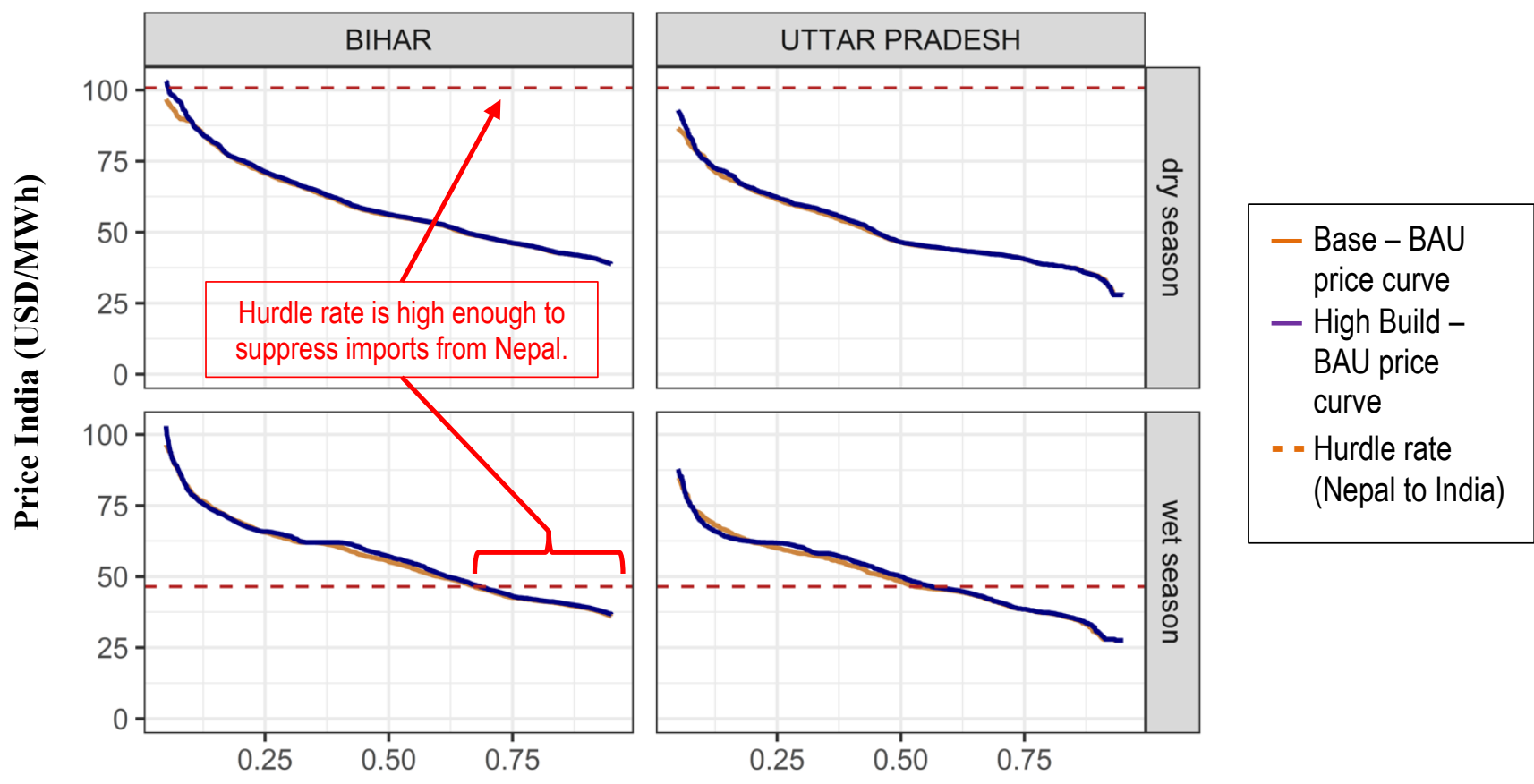

Fractions of Periods

Figure 4. Price in Bihar and Uttar Pradesh relative to hurdle rate on Nepal's exports by season, Base - BAU and High Build - BAU scenarios.

Note: Duration curve excludes the highest $5 \%$ and the lowest $5 \%$ of values.

\subsubsection{Electricity Generation by Resource}

In the High Build-BAU scenario, a 59.3\% increase in installed hydro capacity in Nepal results in a $10.7 \%$ increase in annual hydro generation. The additional hydro capacity is underutilized (despite its low cost) due in part to the lack of demand for the added energy within Nepal, physical transmission constraints, and periods when hurdle rates make CBET uneconomic. This results in curtailment, or spilling, of the extra hydro energy. Figure 5 shows annual generation and hydro curtailment in Nepal for both the Base-BAU and High Build-BAU scenarios. 

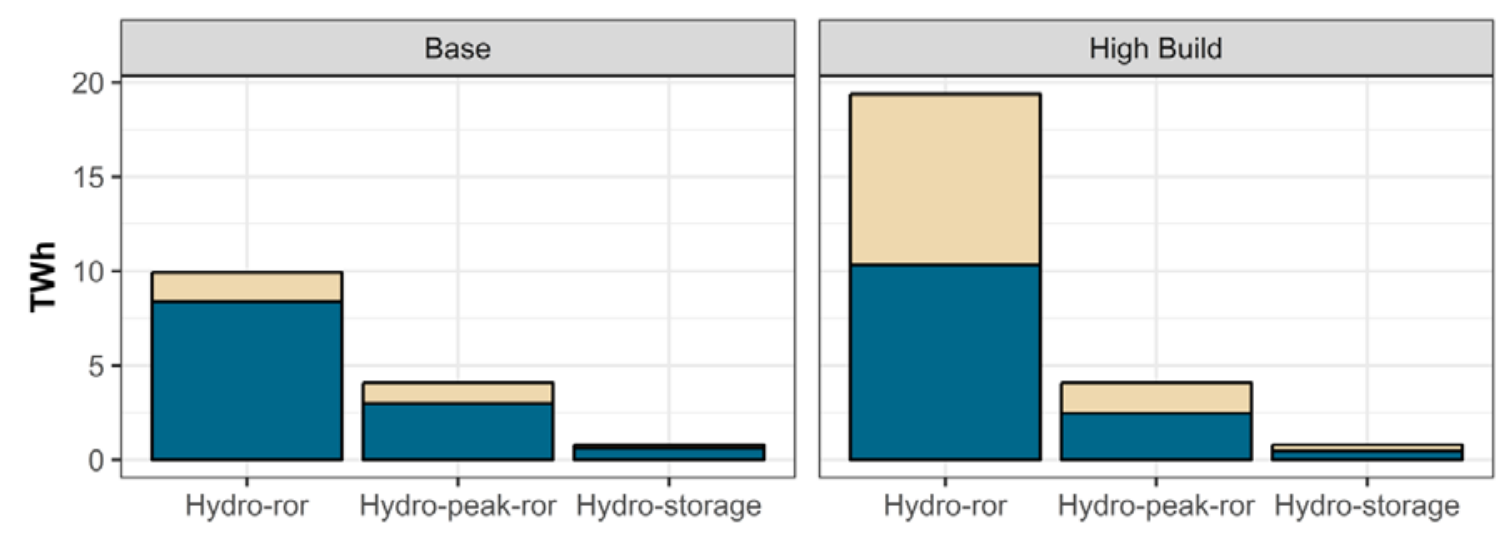

Curtailment $\square$ Generation

Figure 5. Nepal hydro generation and curtailment by resource type, Base-BAU, and High BuildBAU scenarios

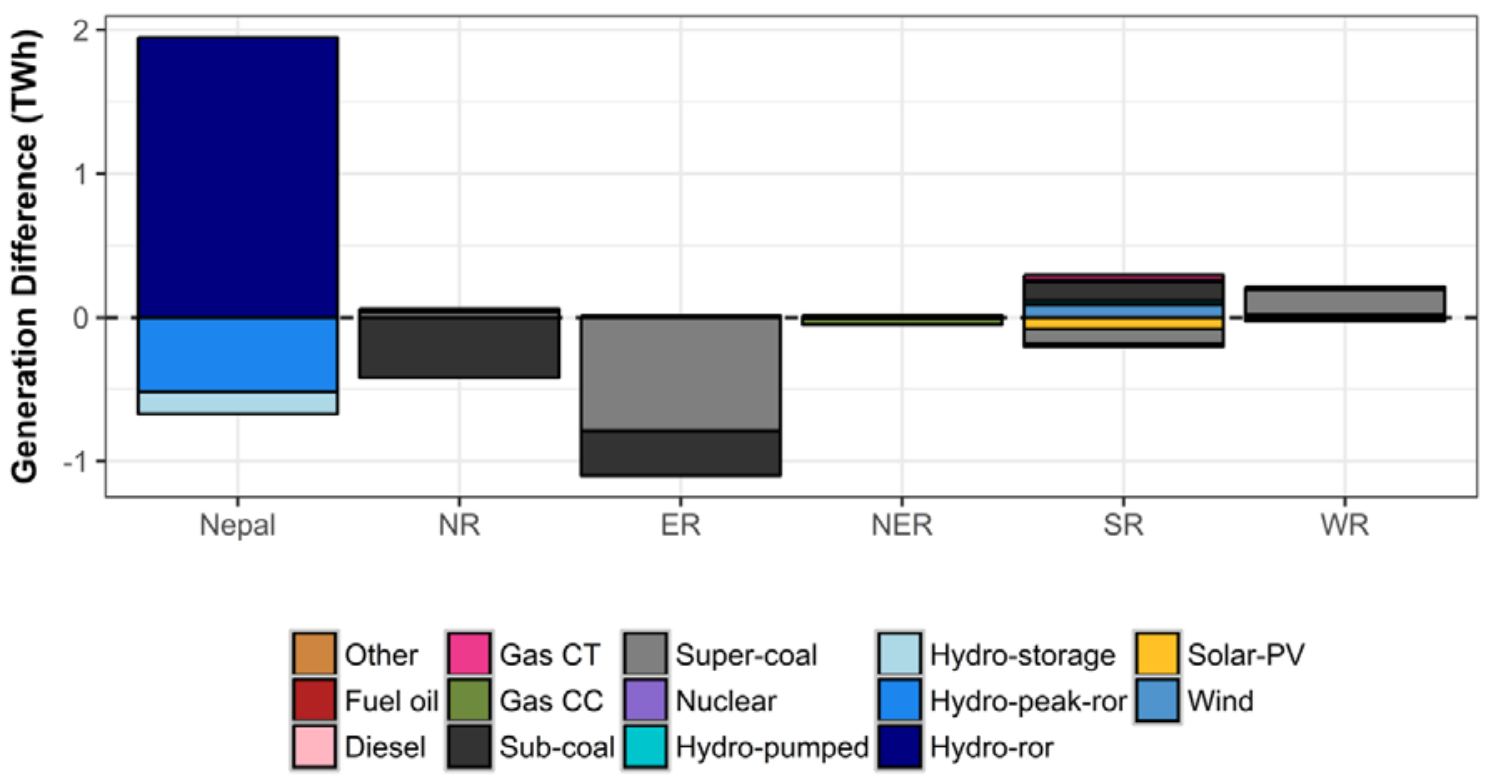

Figure 6. Difference in generation in the High Build-BAU scenario compared to the Base-BAU scenario, by region.

Note: Indian regions: NR - Northern region; ER - Eastern region; NER - Northeastern region: SR - Southern region; WR - Western region. Negative generation means there is less in the High Build-BAU scenario than in Base-BAU; positive means more.

All of the increased capacity in the High Build-BAU scenario is RoR hydro, which is less flexible operationally than hydro with storage. Whatever generation potential is available must be used immediately or forfeited. Therefore, the increased RoR energy combined with relatively low demand and export potential leads to a substantial amount of unused RoR capability. The impact on peaking RoR and hydro with storage is smaller. Across all hydro technologies, curtailment of hydro energy is more than $45 \%$ in the High Build-BAU scenario compared to less than $20 \%$ in the Base-BAU scenario. 
Despite the higher curtailment levels, more hydro capacity increases Nepal's net exports to India from 1.7 TWh in the Base-BAU scenario to 3.0 TWh in the High Build-BAU scenario. The additional 1.3 TWh of net exports primarily displace coal generation in India's Eastern and Northern regions. Figure 6 shows the change in generation in Nepal and in the five Indian power grid regions between the Base-BAU and High Build-BAU scenarios. Reduced coal generation in Bihar accounts for more than $62 \%$ of the decrease in coal generation for all of India. The average variable cost of coal generation in Bihar is $54.7 \%$ higher than in the rest of India.

\subsubsection{Energy Flow between Nepal and India}

Under the High Build-BAU scenario, Nepal increases its annual exports to India and reduces its imports. Compared with the Base-BAU scenario, exports increase from 2,000 GWh to 3,200 GWh and imports fall from $400 \mathrm{GWh}$ to $300 \mathrm{GWh}$.

Energy flows between Nepal and India vary seasonally and hourly in both scenarios. India's greatest demand for power imports from Nepal tends to occur in the early evening and be negligible during the day. More hydro capability in Nepal allows an even higher level of export to India during the evening and early morning hours, as shown in Figure 7.
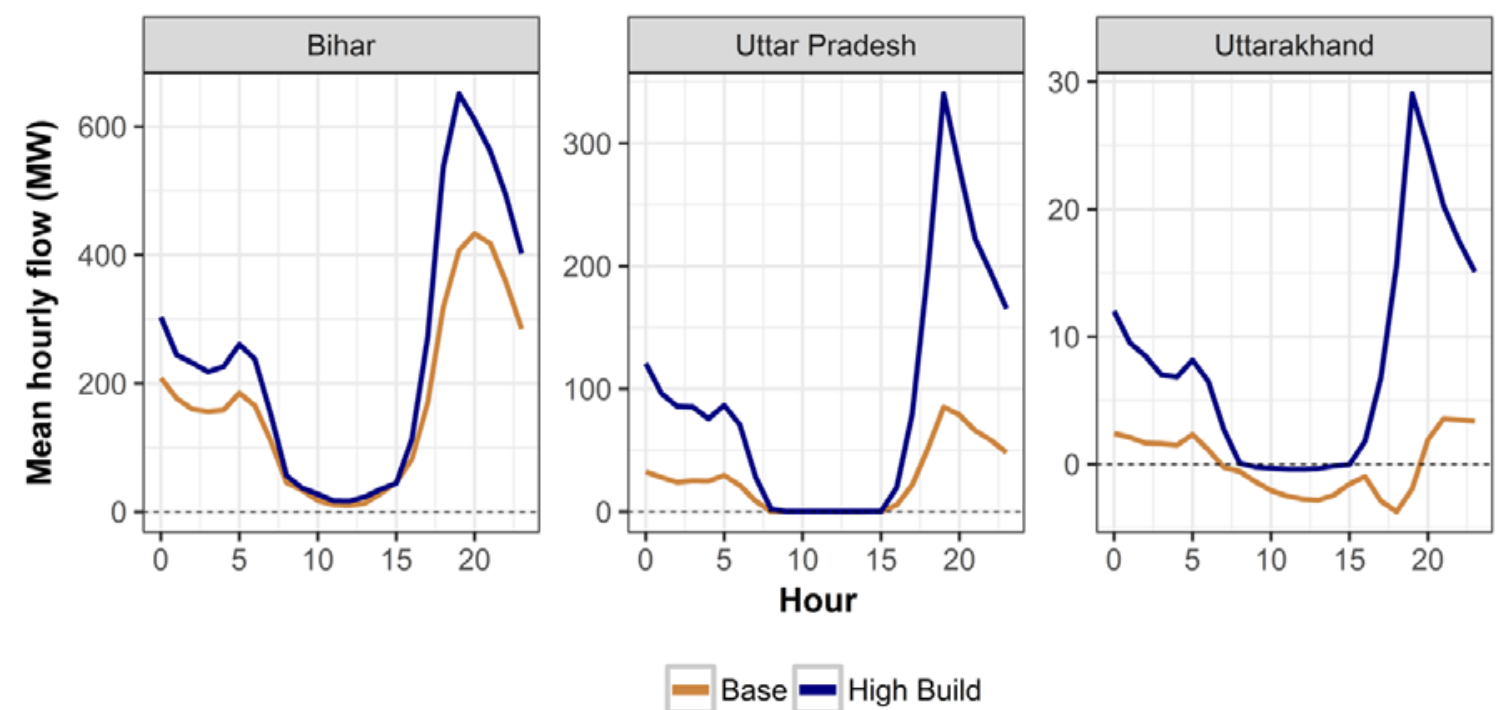

Figure 7. Average hourly net interchange between Nepal and India by Indian state, Base-BAU, and High Build-BAU.

Note: Positive flows indicate energy transfer from Nepal to India. Each state has its own vertical axis scale to illustrate scenario differences. 


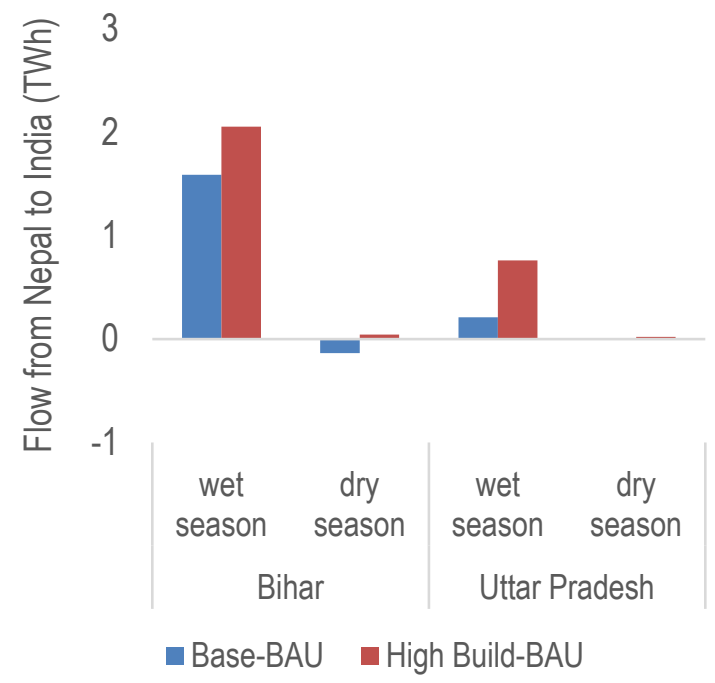

Figure 8. Seasonal flows from Nepal to Indian states

Nepal's monthly net interchange with India is generally limited to the wet season months (June through November), when Nepal has the most available hydro. The High Build-BAU scenario results in significantly higher wet-season flows from Nepal to India despite the hurdle rates, as shown in Figure 8. The increase was proportionately larger for Uttar Pradesh, where CBET increased nearly fourfold.

\subsubsection{Transmission Congestion}

Transmission between Nepal and Uttar Pradesh is never congested. On the other hand, congestion between Nepal and Bihar increases more than six-fold in the High Build-BAU scenario. All congestion between Nepal and Bihar occurs on the 132-kV lines connecting Parwanipur to Raxaul and Gandak to Ramnagar, not on the major 400-kV corridor between Muzaffarpur and Dhalkebar. Table 10 provides the annual hours of transmission congestion from Nepal to each neighboring Indian state.

The lack of congestion on the border between Uttar Pradesh and western Nepal could result from transmission limits within Nepal that prevent electricity generated in the eastern part of Nepal from reaching the western part for export. However, the $400-\mathrm{kV}$ connection from Butwal to Gorakhpur (included in all scenarios) never saw congestion so it is assumed that the current plans are sufficient to accommodate exports from Nepal.

Only one transmission line inside Nepal is congested more than $1 \%$ of the time in the High Build-BAU scenario. ${ }^{11}$ The line links not-yet-completed hydroelectric projects in the Koshi river basin to the rest of the grid. Upgrades to this existing transmission pathway could help reduce total production costs as new hydro projects become operational.

\footnotetext{
11 The thermal loading limits of transformers is not considered in the DC-optimal power flow.
} 
Table 10. Hours of Congestion on Transmission between Nepal and India Base and High Build Scenario

\begin{tabular}{lcc}
\hline Interface & Base-BAU & High Build-BAU \\
\hline Nepal $\rightarrow$ Bihar & 240 & 1,498 \\
Nepal $\rightarrow$ Uttar Pradesh & 0 & 0 \\
Nepal $\rightarrow$ Uttarakhand & 0 & 229 \\
\hline
\end{tabular}

\subsection{Increased Nepal Hydropower with Coordinated Operations}

As seen in Section 3.1, hurdle rates on flows between Nepal and India restricts CBET. This section reexamines the Base and High Build scenarios using rates that treat Nepal the same as any Indian state - i.e., allowing price signals to work in a nondiscriminatory manner across the two countries. Table 11 summarizes the scenarios involved.

Table 11. Scenarios Examined, Coordinated Operations

\begin{tabular}{|c|c|c|c|c|}
\hline Scenario & $\begin{array}{l}\text { Hydro } \\
\text { Buildout }\end{array}$ & Hurdle Rates & $\begin{array}{l}\text { India Wind and } \\
\text { Solar Capacity }\end{array}$ & Bangladesh \\
\hline Base-BAU & $2,839 \mathrm{MW}$ & \multirow{2}{*}{ BAU } & \multirow{4}{*}{$160 \mathrm{GW}$} & \multirow{4}{*}{ Not included } \\
\hline High Build-BAU & $4,551 \mathrm{MW}$ & & & \\
\hline Base-CO & 2,839 MW & \multirow{2}{*}{$\mathrm{CO}$} & & \\
\hline High Build-CO & $4,551 \mathrm{MW}$ & & & \\
\hline
\end{tabular}

\subsubsection{Electricity Production Cost}

Coordinated Operations greatly increase the production cost savings possible in the High Build scenario. Moving from the Base scenario to either High Build or Coordinated Operations scenarios alone results in some production cost savings - \$106 million or \$120 million, respectively. However, Coordinated Operations alongside High Build more than doubles production cost savings to $\$ 462$ million, or $1.3 \%$ relative to the Base-BAU scenario. The positive interaction between the two, illustrated in Figure 9, is due to the coincidence of surplus hydro availability in Nepal (High Build) and improved trading opportunities with India (Coordinated Operations), which together facilitate higher exports from Nepal to India and reduce overall production costs. 


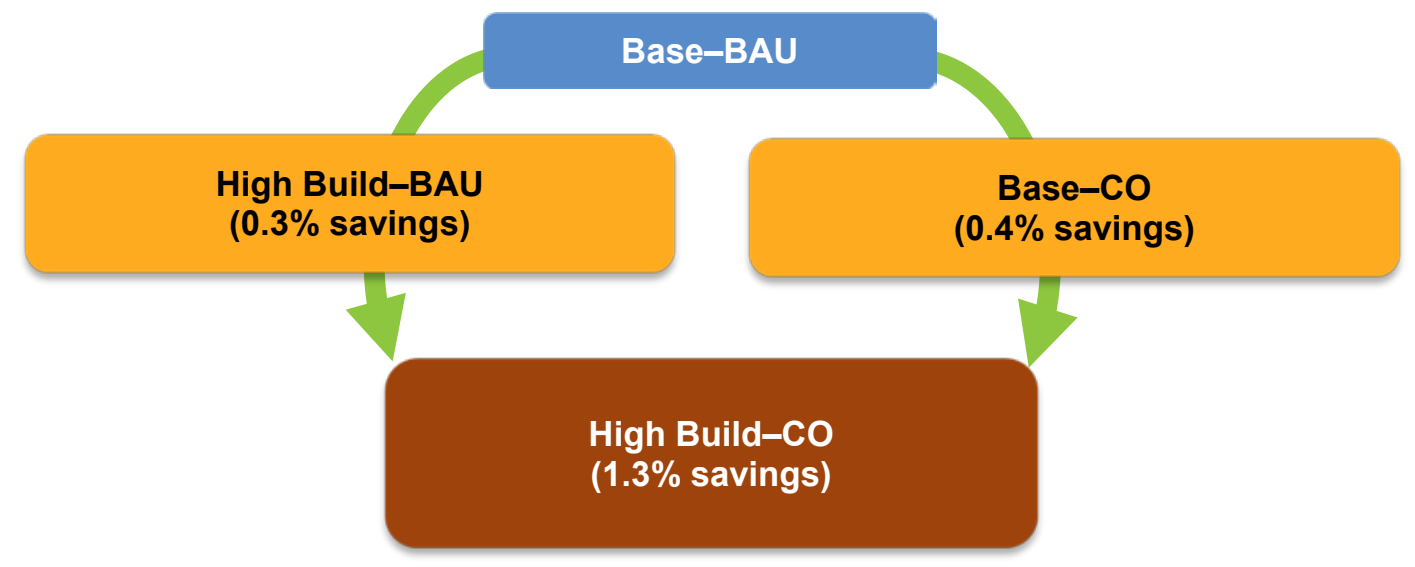

Figure 9. Production cost savings for Nepal and India due to Coordinated Operations, High Build

Regionally, the Northern and Eastern regions see the largest production cost savings when moving from the Base to High Build scenario with Coordinated Operations: $\$ 134$ million (1.6\%) and \$194 million (3.8\%), respectively. However, production costs in the more distant Western region also fall by $\$ 111$ million $(0.9 \%)$. The reduction in Western region's production cost indicates that large-scale hydro imports from Nepal can affect energy flows within India.

Table 12. Electricity Production Costs in the Coordinated Operations Scenarios, and Difference from BAU Scenarios (USD millions)

\begin{tabular}{lcccccc}
\hline & \multicolumn{2}{c}{ Base-CO } & & \multicolumn{3}{c}{ High Build-CO } \\
\cline { 2 - 3 } & $\begin{array}{c}\text { Production } \\
\text { Cost }\end{array}$ & $\begin{array}{c}\text { Difference, } \\
\text { Base-BAU (\%) }\end{array}$ & & $\begin{array}{c}\text { Production } \\
\text { Cost }\end{array}$ & $\begin{array}{c}\text { Difference, High } \\
\text { Build-BAU (\%) }\end{array}$ & $\begin{array}{c}\text { Difference, } \\
\text { Base-BAU (\%) }\end{array}$ \\
\hline Eastern region & $\$ 5,025$ & $-\$ 57(-1.1 \%)$ & & $\$ 4,888$ & $-\$ 128(-2.6 \%)$ & $-\$ 194(-3.8 \%)$ \\
Northern region & $\$ 8,139$ & $-\$ 31(-0.4 \%)$ & & $\$ 8,036$ & $-\$ 107(-1.3 \%)$ & $-\$ 134(-1.6 \%)$ \\
Rest of India & $\$ 20,961$ & $-\$ 32(-0.2 \%)$ & & $\$ 20,858$ & $-\$ 121(-0.6 \%)$ & $-\$ 135(-0.6 \%)$ \\
India + Nepal & $\$ 34,125$ & $\mathbf{- \$ 1 2 0 ( - 0 . 4 \% )}$ & & $\$ 33,783$ & $-\$ 356(-1.0 \%)$ & $-\$ 462(-1.3 \%)$ \\
\hline
\end{tabular}

\subsubsection{Electricity Generation by Resource}

Lower hurdle rates reduce hydro curtailment in Nepal and increase exports from Nepal to India. The contrast is particularly prominent in the High Build scenario, as shown in Figure 10, which compares annual hydro generation and curtailment in Nepal across each scenario. In the Base scenario, Coordinated Operations leads to a reduction in curtailed energy of $10.7 \%$, however, in the High Build scenario, Coordinated Operations lead to a reduction in curtailed hydro of six times. 


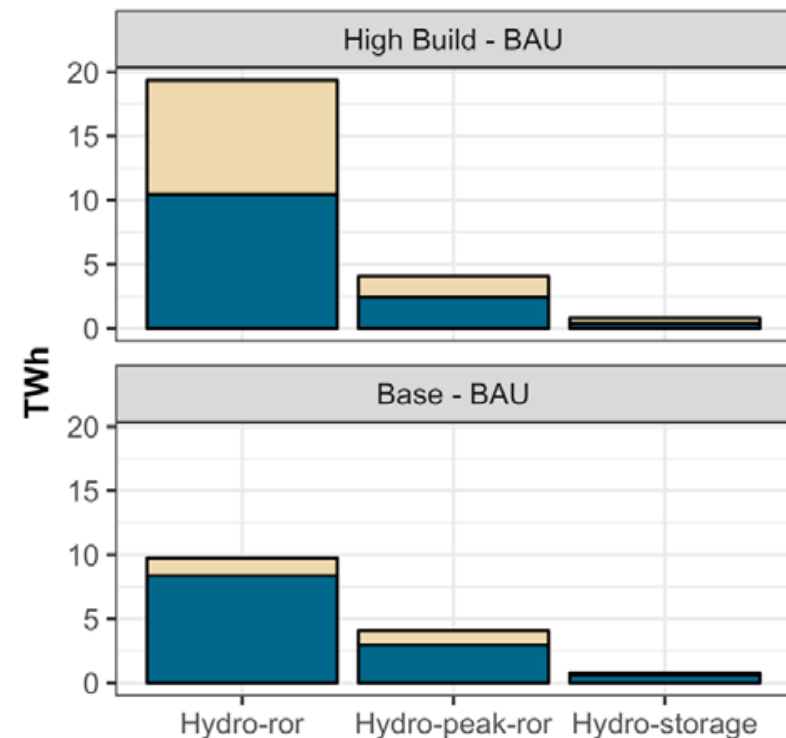

Hydro-ror Hydro-peak-ror Hydro-storage
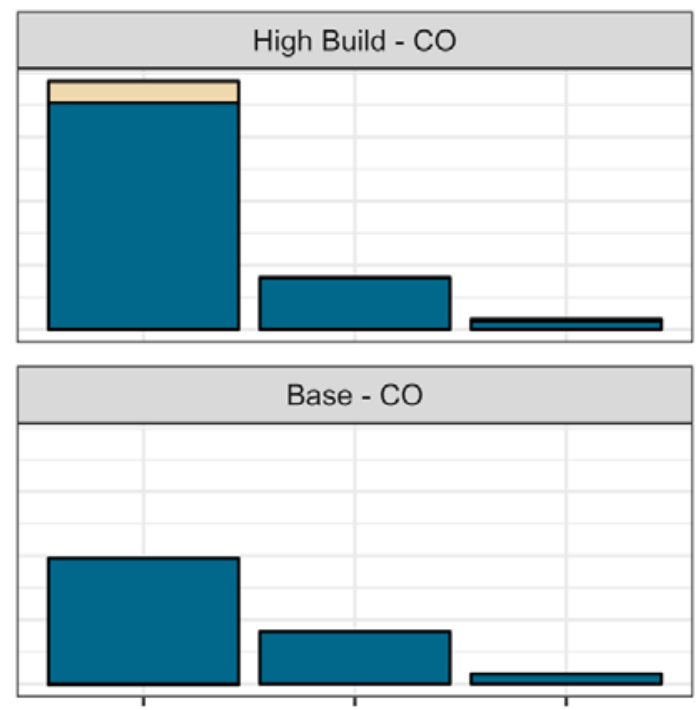

Hydro-ror

$\square$ Curtailment $\square$ Generation

Figure 10. Nepal hydro generation and curtailment by resource type, all scenarios

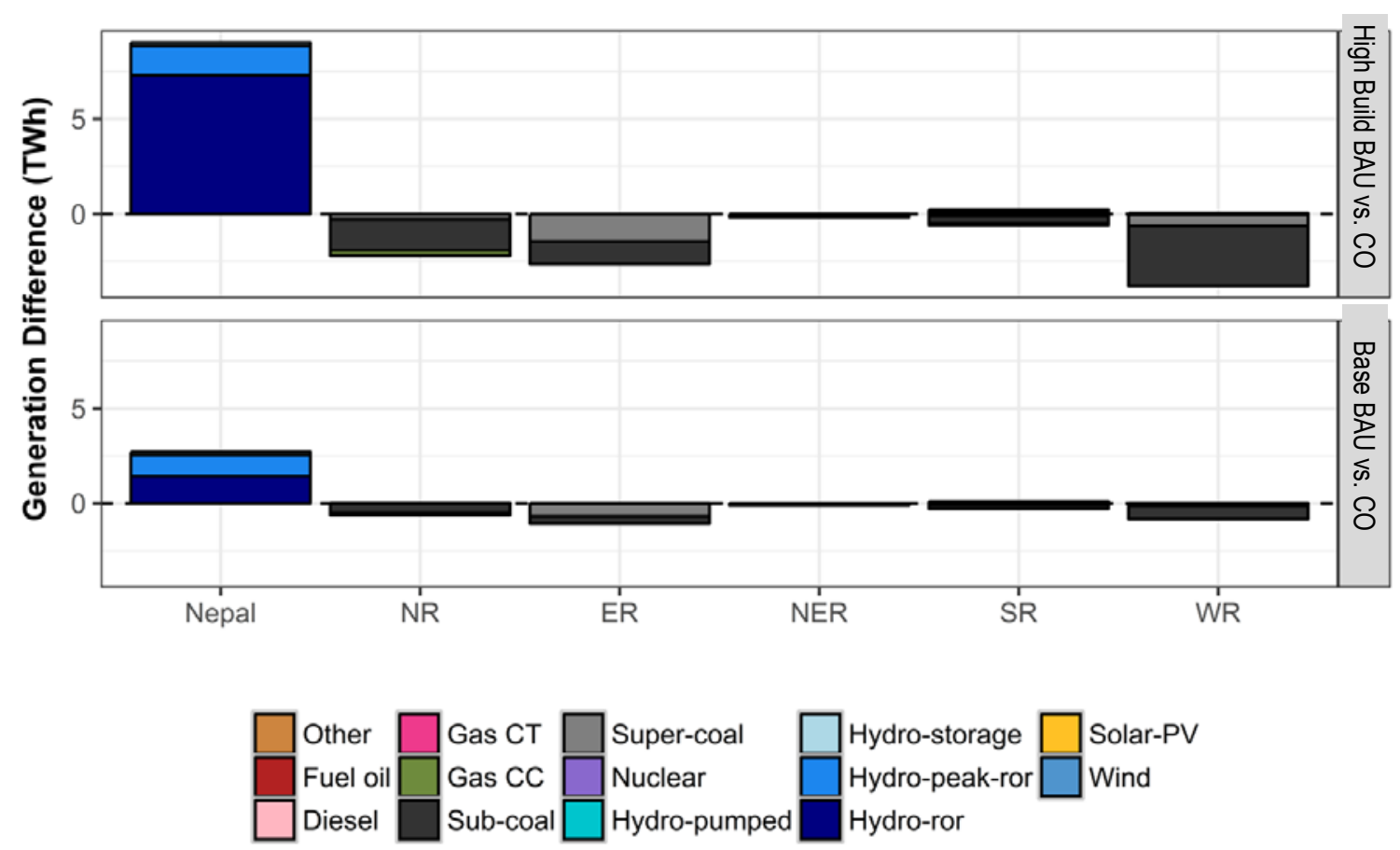

Indian dispatch center regions: NR - Northern; ER - Eastern; NER - Northeastern; SR - Southern; WR - Western

Figure 11. Difference in generation, by fuel type, due to Coordinated Operations for both hydro capacity scenarios.

Note: Negative generation means there is less generation with Coordinated Operations; positive means more. 
Nepal increases net exports to India by 9.0 TWh when moving from the Base-CO to High Build $\mathrm{CO}$ scenario. This is nearly three times what imports would be if Nepal simply increased its hydro capacity in the absence of Coordinated Operations. Figure 11 illustrates the effects that Coordinated Operations could have under a range of hydro buildouts in Nepal. Coal generation in the Northern and Eastern regions adjacent to Nepal decline as expected under either buildout level. However, a High Build of Nepal hydro also accelerates a reduction in coal generation in the Western Region in large part because the Northern Region replaces 3.5\% of what it imports from the Western region with more hydro imports from Nepal compared to the High Build-BAU scenario. Nepal can more effectively compete with the Western region as a supplier of energy to the Northern region.

\subsubsection{Energy Flow between Nepal and India}

With the combination of Coordinated Operations and High Build, Nepal continues to maximize exports during peak load times, but also consistently exports more than $1 \mathrm{GW}$ to India between the morning and evening peaks. Figure 12 shows the Coordinated Operations scenarios alongside the BAU scenarios described in the previous section. Overall, CBET from Nepal to India is more than $50 \%$ higher than it would be if hydro capacity were to increase without reductions in hurdle rates.

The increase in exports to Uttar Pradesh and Uttarakhand is especially pronounced. CBET from Nepal to Uttar Pradesh increases 567\% (4.4 TWh) when a high buildout of hydro in Nepal is augmented by Coordinated Operations. The increased volume to both Indian states is also closer to a baseload profile than exports under the other scenarios, which could contribute to the Western Region's reduction in coal generation and exports to the Northern Region.

Coordinated Operations allows Nepal to become a net energy exporter during the dry season (December-May) but it also has an effect on Nepal's imports from India under conditions of lower hydro buildout. Coordinated Operations increases the value of storage-augmented hydro during peak load hours. As these resources are held so they can be dispatched during peak demand periods, imports from India increase to meet Nepal's domestic generation gap midday. 


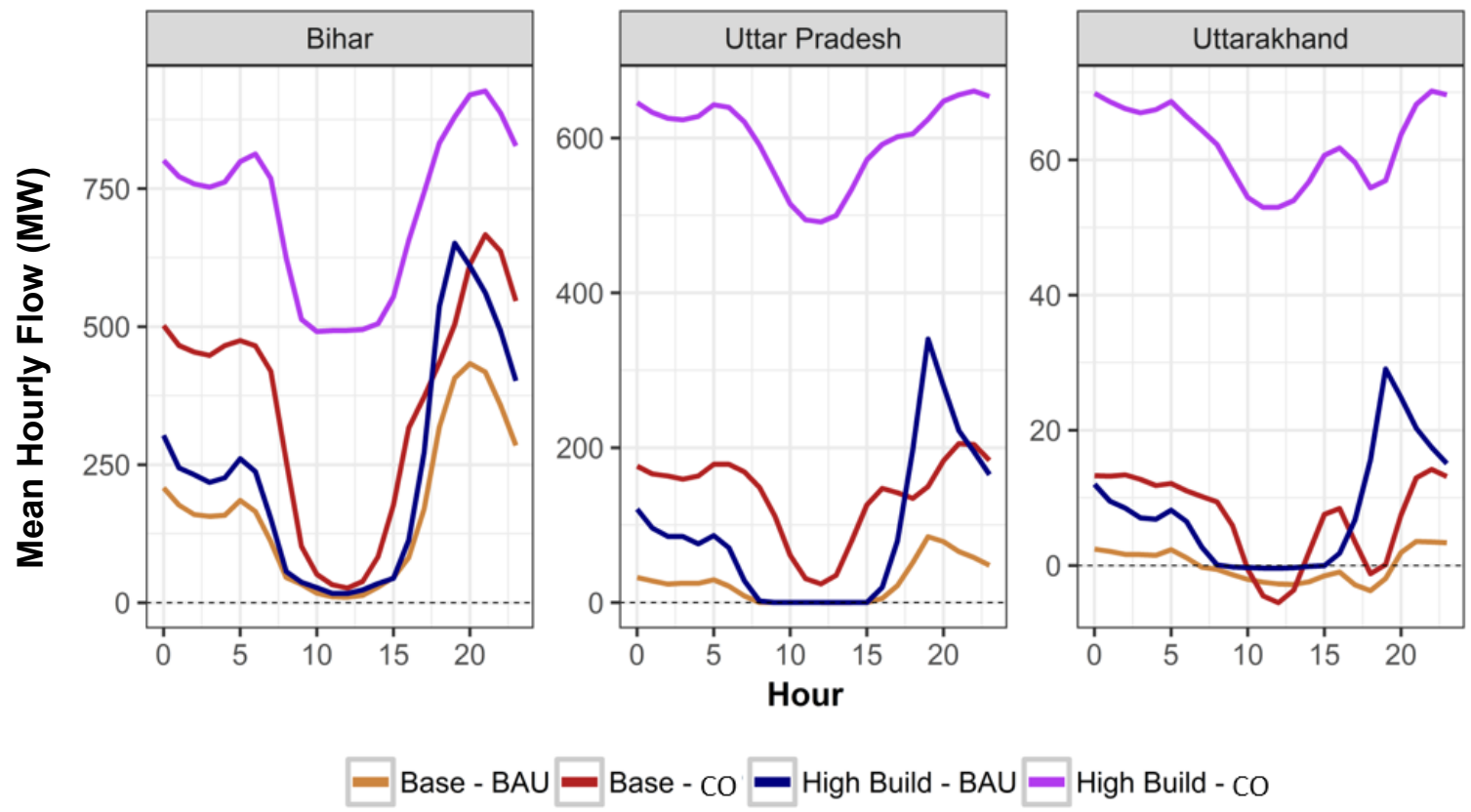

Figure 12. Average hourly net interchange between Nepal and India by Indian state, all scenarios.

Note: Positive flows indicate energy transfer from Nepal to India. Each state has its own vertical axis scale to illustrate scenario differences.

Put another way, the shift in utilization represents time-related price arbitrage between the middle of the day and the evening peak hours. Figure 13 uses dispatch on March 15 to illustrate the phenomenon. From 10 a.m. to 3 p.m. under the Base-BAU scenario, LMPs average about \$41/MWh in Bihar and \$36/MWh in Uttar Pradesh. From 6 p.m. to 9 p.m. that same day, the average is $\$ 86 / \mathrm{MWh}$ and $\$ 62 / \mathrm{MWh}$, respectively. Increasing coordination allows Nepal's peaking RoR and storage hydro plants to shift their generation to peak hours when it is most valuable. This shift tends to result in lower LMPs on the Indian side of the border.

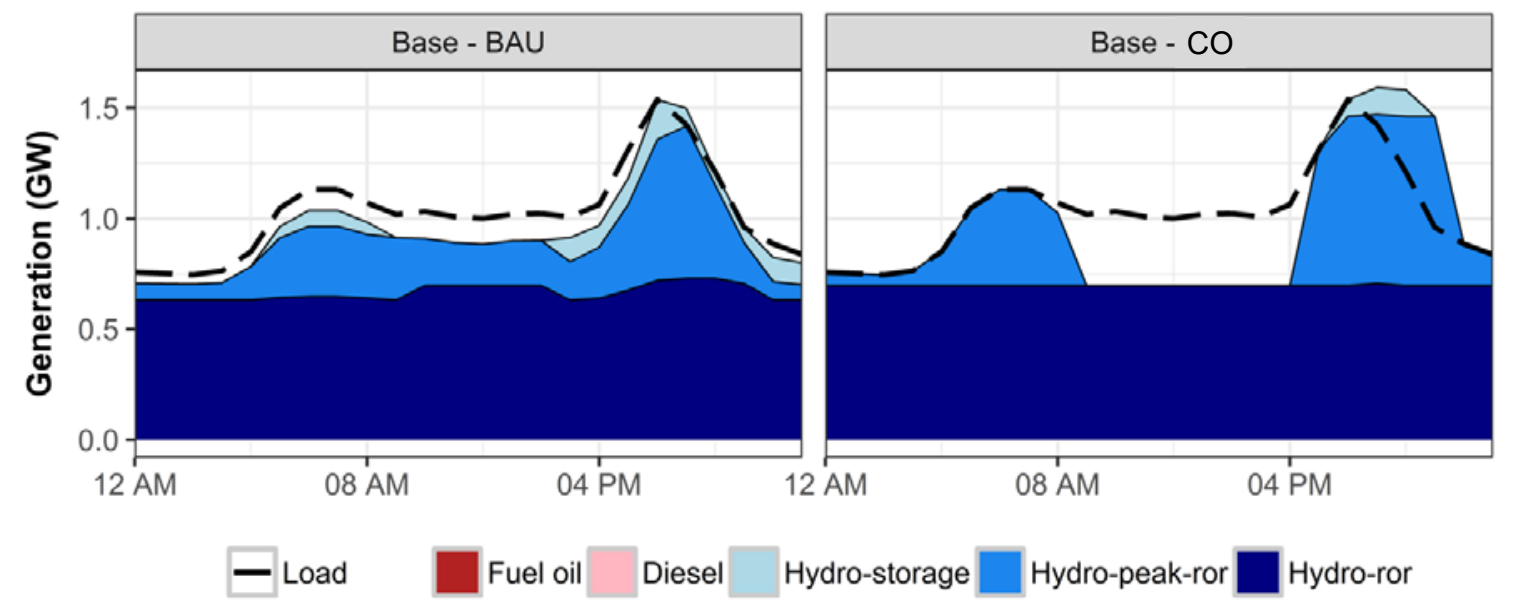

Figure 13. Generator dispatch and load in Nepal on March 15, Base scenario with and without Coordinated Operations 


\subsubsection{Transmission Congestion}

Transmission congestion between Nepal and the Indian states with which it exchanges power is highest when high buildout of Nepal hydropower is combined with Coordinated Operations.

Table 13 provides annual hours of transmission congestion between Nepal and each Indian state. As in the previous section, transmission congestion between Nepal and India occurs only on the 132-kV lines between Parwanipur - Raxaul, Gandak - Ramnagar and Mahendranagar Tanakpur rather than on the higher-capacity $400-\mathrm{kV}$ lines.

Table 13. Transmission Congestion between Nepal and Neighboring Indian States, All Scenarios

\begin{tabular}{lcccc}
\hline Interface & $\begin{array}{c}\text { Base - BAU } \\
\text { (hrs.) }\end{array}$ & $\begin{array}{c}\text { Base - CO } \\
\text { (hrs.) }\end{array}$ & $\begin{array}{c}\text { High Build - BAU } \\
\text { (hrs.) }\end{array}$ & $\begin{array}{c}\text { High Build-CO } \\
\text { (hrs.) }\end{array}$ \\
\hline Nepal $\rightarrow$ Bihar & 241 & 1243 & 1498 & 5541 \\
Nepal $\rightarrow$ Uttar Pradesh & 0 & 0 & 0 & 0 \\
Nepal $\rightarrow$ Uttarakhand & 0 & 0 & 229 & 1900 \\
\hline
\end{tabular}

\subsection{Nepal Hydropower with Renewable Energy Integration in India}

The previous sections suggest the importance of increased coordination in maximizing CBET benefits for both Nepal and India, with the benefits to India accruing mostly in states close to Nepal. In this section we examine whether greater hydropower development in Nepal could affect India's ability to integrate high penetrations of wind and solar power nationwide at lower cost, and whether coordinated operations could have a comparable effect on those benefits.

This section examines how different levels of CBET, as represented by extent of coordination with the High Build scenario, impact the challenges associated with operating a high RE power system in India, as represented by two levels of installed RE capacity. Table 14 describes the scenarios compared in this section.

Table 14. Scenarios Examined, RE Integration

\begin{tabular}{|c|c|c|c|c|c|}
\hline Scenario & $\begin{array}{l}\text { Hydro } \\
\text { Buildout }\end{array}$ & Hurdle Rates & $\begin{array}{c}\text { India Solar } \\
\text { Capacity }\end{array}$ & $\begin{array}{l}\text { India Wind } \\
\text { Capacity }\end{array}$ & Bangladesh \\
\hline High Build--BAU - Low RE & \multirow{4}{*}{$\begin{array}{c}\text { High } \\
(4,551 \mathrm{MW})\end{array}$} & \multirow{2}{*}{ BAU } & $20 \mathrm{GW}$ & $50 \mathrm{GW}$ & \multirow{4}{*}{ Not included } \\
\hline High Build-BAU & & & $100 \mathrm{GW}$ & $60 \mathrm{GW}$ & \\
\hline High Build-CO - Low RE & & \multirow{2}{*}{$\begin{array}{l}\text { Coordinated } \\
\text { Operations }\end{array}$} & $20 \mathrm{GW}$ & $50 \mathrm{GW}$ & \\
\hline High Build-CO & & & $100 \mathrm{GW}$ & $60 \mathrm{GW}$ & \\
\hline
\end{tabular}

\subsubsection{Electricity Production Cost}

Under BAU hurdle rates for CBET and high buildout of hydropower in Nepal, increasing India's wind and solar capacity from $70 \mathrm{GW}$ to $160 \mathrm{GW}$ reduces total production cost. Generation from wind and solar has zero fuel cost, and therefore contributes less to total production cost compared to the thermal generation that it displaces. The BAU cost reduction (moving from the lower to the higher level of RE capacity) is $14.9 \%$ for the modeled region. The cost reductions 
are almost the same (within $0.1 \%$ ) if the above RE capacity changes occur in the context of Coordinated Operations between Nepal and India.

\subsubsection{Electricity Generation by Resource and RE Curtailment}

Figure 14 shows annual generation by resource type in both Nepal and India across the four scenarios. As discussed in Section 3.2, Nepal's hydro generation rises when BAU hurdle rates are replaced by Coordinated Operations, which accounts for most of the differences between the two pairs of scenarios.

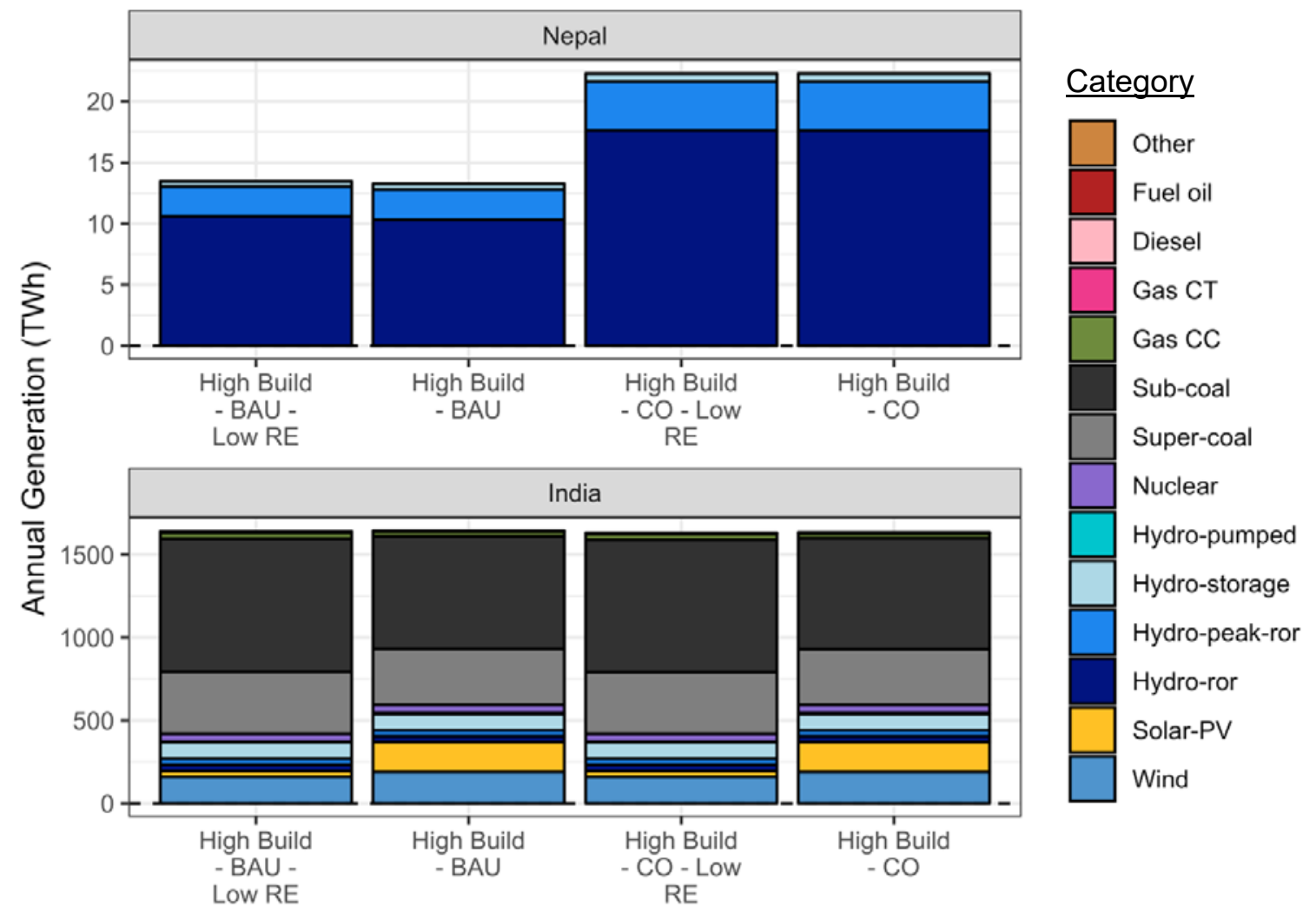

Figure 14. Annual generation in Nepal and India by resource type, all scenarios

When CBET hurdle rates are held constant at BAU levels, more wind and solar generation in India correlates with a $1.5 \%$ drop in Nepal's hydro generation. This suggests that India's increased wind and solar generation displaces some of Nepal's potential hydropower exports to India because Nepal's hydro cannot compete as effectively in the Indian market due to the high hurdle rates.

Under Coordinated Operations, Nepal's hydro generation remains unchanged when India's renewable energy penetration level increases. Therefore, Nepal's vulnerability to hydro curtailment depends less on the amount of renewable generation in India and more on transaction costs for CBET between the two countries.

India's wind and solar penetration and its renewable energy curtailment levels are unaffected by Nepal hydropower even with Coordinated Operations. The increased flow of hydropower from Nepal enabled by Coordinated Operations primarily displaces generation from India's thermal 
plants and does not affect RE curtailment, which is $1.3 \%$ at wind and solar capacity of $160 \mathrm{GW}$. The new hydro generation in the High Build scenario is primarily run-of-river, which cannot be stored and delivered when its value for RE integration is greatest, which in this case is midday to reduce RE curtailments in India. For an analysis of how RE curtailment can occur in India under high RE penetrations, see Palchak et al. 2017.

\subsubsection{Energy Flow between Nepal and India}

Larger penetration levels of RE in India slightly reduce imports from Nepal under coordinated operations and at a modestly larger reduction under BAU hurdle rates. Under BAU hurdle rates, a system with $160 \mathrm{GW}$ wind and solar capacity in India reduces flows from Nepal by about 197 GWh compared to India at $70 \mathrm{GW}$ wind and solar. The reduction occurs because higher hurdle rates handicap the ability of Nepal's hydropower exports to compete in India when higher wind and solar penetrations reduce marginal costs.

Most of this trade reduction is recovered with Coordinated Operations, however. The 12.3\% drop in exports to Uttar Pradesh and the 3.5\% drop in exports to Bihar both disappear under Coordinated Operations. Table 15 summarizes changes in net flows between Nepal and each Indian state.

Table 15. Net Flows between Nepal and Indian States with Different Renewable Energy Levels in India (GWh)

\begin{tabular}{ccccc} 
& & \multicolumn{2}{l}{ India Wind and Solar } & \\
\cline { 3 - 4 } Area & Scenario & $\mathbf{7 0 ~ G W}$ & $\mathbf{1 6 0} \mathbf{~ G W}$ & Change \\
\hline \multirow{3}{*}{ Bihar } & BAU & 2,176 & 2,099 & $-3.50 \%$ \\
& CO & 6,206 & 6,213 & $0.10 \%$ \\
& Change & $185 \%$ & $196 \%$ & \\
\hline \multirow{2}{*}{ Uttar } & BAU & 893 & 783 & $-12.30 \%$ \\
Pradesh & CO & 5,224 & 5,222 & $0.00 \%$ \\
& Change & $485 \%$ & $567 \%$ & \\
\multirow{2}{*}{ Uttarakhand } & BAU & 79 & 69 & $-12.70 \%$ \\
& CO & 547 & 545 & $-0.4 \%$ \\
Nepal-India & Change & $596 \%$ & $687 \%$ & \\
Total & BAU & 3,148 & 2,951 & $-6.26 \%$ \\
& CO & 11,977 & 11,980 & $0 \%$ \\
& Change & $280 \%$ & $306 \%$ & \\
\hline
\end{tabular}

Note: A positive change indicates that Nepal's net exports to India increase, and vice versa.

The main difference in energy flows between Nepal and India when moving from $70 \mathrm{GW}$ to 160 GW wind and solar capacity is a slight dip in Nepal's daytime net exports and corresponding rise in its nighttime net exports. India's increased daytime solar energy in the $160 \mathrm{GW}$ scenario explains the changed behavior. Figure 15 illustrates the effect under Coordinated Operations. 

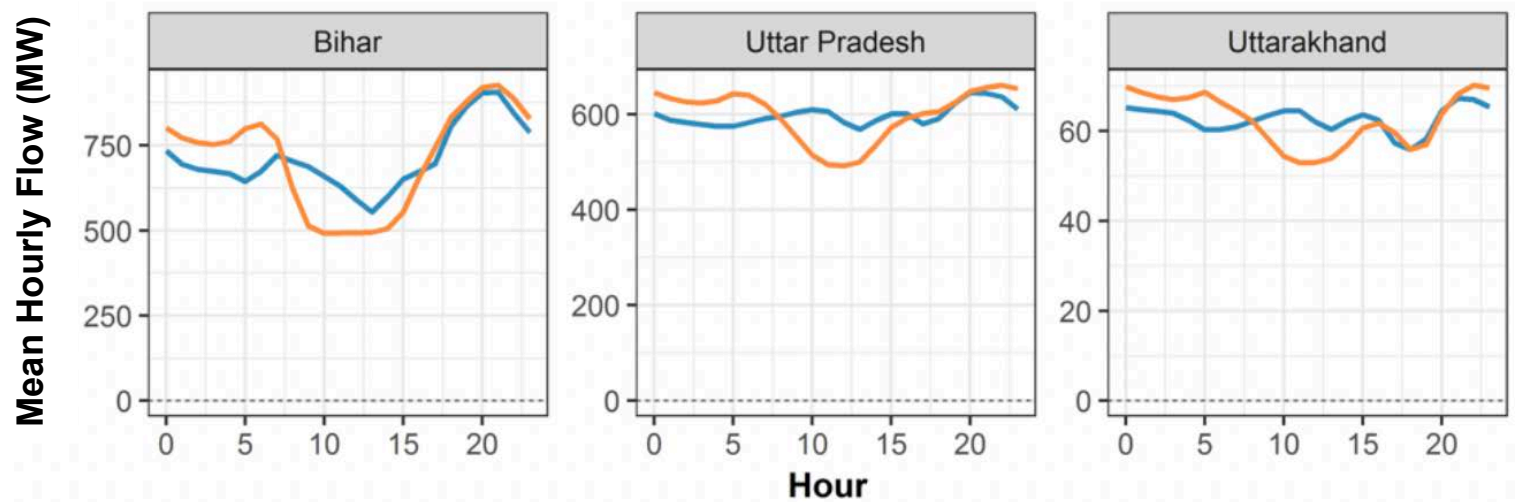

High Build -
CO- Low RE

Figure 15. Average hourly net interchange between Nepal and Indian state, High Build-CO-Low RE vs. High Build-CO.

Note: Positive flows indicate energy transfer from Nepal to India. Each state has its own vertical axis scale to illustrate scenario differences.

\subsection{Increased Trade with Bangladesh}

This section analyzes the impact of increased trade between Nepal and Bangladesh. While we do not explicitly model a contract between Nepal and Bangladesh, we add 1,000 MW of constant load in West Bengal at the DC tie with Bangladesh and examine how varying levels of coordination within the BBIN region affect the ability of Nepal to serve the increased demand.

Existing CBET hurdle rates limit the flow of hydropower from Nepal to Bangladesh. In the scenario based on high buildout of Nepal hydropower and BAU hurdle rates, Nepal exports 3.0 TWh to India. This is significantly less than the 8.7 TWh that would move through the DC flowgate from West Bengal to Bangladesh if Nepal were to supply the constant 1,000 MW of contracted capacity with its domestic generators. This suggests that no independent hydroelectric power producer in Nepal would be capable of fully meeting the contracted supply unless it operated under special CBET provisions, had a dedicated transmission line through India to Bangladesh, or CBET hurdle rates were lowered more generally. Instead, the actual power would come from India, primarily by increasing generation at coal plants in the Eastern region.

On the other hand, 12 TWh of power moves from Nepal into India under High Build-CO scenario, sufficient for supplying all contracted power to Bangladesh. We therefore use the High Build scenarios to examine the potential flow of hydropower from Nepal to Bangladesh. To evaluate the impact on total production costs of increased levels of coordination along with a Bangladesh supply contract, we use the High Build-BAU scenario for comparison. Table 16 summarizes the scenarios examined. 
Table 16. Scenarios Examined, Bangladesh, BAU, and Coordinated Operations

\begin{tabular}{lcccc}
\hline Scenario & Hydro Buildout & Hurdle Rates & $\begin{array}{c}\text { India Wind and } \\
\text { Solar Capacity }\end{array}$ & Bangladesh \\
\cline { 1 - 3 } High Build-BAU & $\begin{array}{c}\text { High } \\
(4,551 \mathrm{MW})\end{array}$ & BAU & $160 \mathrm{GW}$ & Not included \\
\cline { 1 - 3 } Bangladesh-BAU & $\begin{array}{c}\text { High } \\
\text { High Build-CO }\end{array}$ & $\begin{array}{c}\text { Coordinated } \\
\text { Operations }\end{array}$ & $160 \mathrm{GW}$ & Included \\
\cline { 1 - 3 } Bangladesh-CO & $(4,551 \mathrm{MW})$ & Not included & Included \\
\hline
\end{tabular}

\subsubsection{Electricity Production Cost}

Adding a constant 1,000 MW of load anywhere on the system would naturally increase generation and, therefore, total production costs. Holding BAU hurdle rates and everything else unchanged, the added load in Bangladesh would increase total production costs in the Eastern region by $6.4 \%$. Costs would increase $0.2 \%$ for the rest of India. As explained previously, most of the additional load would be met by increasing generation in India rather than using Nepal's hydropower.

However, increasing coordination between Nepal and India along with adding 1,000 MW of load in Bangladesh would allow more low-cost hydropower from Nepal to be exported, offsetting much of the cost of generating additional power in India. Table 17 contrasts production costs under the key scenarios. Including both the supply contract with Bangladesh and Coordinated Operations increases total production costs in the Eastern region by only $3.4 \%$ instead of $6.4 \%$ under BAU.

Table 17. Effect of Increased Generation to Serve Bangladesh on Total Production Costs (USD millions)

\begin{tabular}{lcccc}
\hline & $\begin{array}{c}\text { Bangladesh- } \\
\text { BAU }\end{array}$ & $\begin{array}{c}\text { Difference from High } \\
\text { Build-BAU (\%) }\end{array}$ & $\begin{array}{c}\text { Bangladesh- } \\
\text { CO }\end{array}$ & $\begin{array}{c}\text { Difference from High } \\
\text { Build-BAU (\%) }\end{array}$ \\
\hline Eastern region & $\$ 5,335$ & $\$ 319(6.4 \%)$ & $\$ 5,186$ & $\$ 170(3.4 \%)$ \\
Northern region & $\$ 8,214$ & $\$ 71(0.9 \%)$ & $\$ 8,098$ & $-\$ 54(-0.7 \%)$ \\
Rest of India & $\$ 21,025$ & $\$ 46(0.2 \%)$ & $\$ 20,928$ & $-\$ 51(-0.2 \%)$ \\
India + Nepal & $\$ 34,575$ & $\$ 436(1.3 \%)$ & $\$ 34,212$ & $\$ 73(0.2 \%)$ \\
\hline
\end{tabular}

Average LMPs in Indian states bordering or near Nepal with Coordinated Operations are largely the same with or without the additional flows from West Bengal to Bangladesh.

\subsubsection{Electricity Generation by Resource}

As previously discussed, more CBET coordination results in more hydropower generation in Nepal, making it economic to export more power from run-of-river plants that were previously generating below their full capability. Adding demand to Bangladesh, however, has little additional effect on Nepal's hydropower generation under the Coordinated Operations scenario. In this scenario, 141 out of 165 run-of-river plants are operating at their maximum output with no curtailment. Network congestion within Nepal or between Nepal and India constrains output from many of the remaining plants. Given these constraints, adding a contract with Bangladesh 
does not affect hydro plant utilization in Nepal because, even without the Bangladesh contract, Nepal has adequate outlets for its exports in India.

Instead of adding more hydropower from Nepal, the additional demand in Bangladesh triggers more coal generation in India, most of it on subcritical coal units. Figure 16 shows how resource utilization in India changes with a supply contract with Bangladesh, assuming Coordinated Operations between Nepal and India.
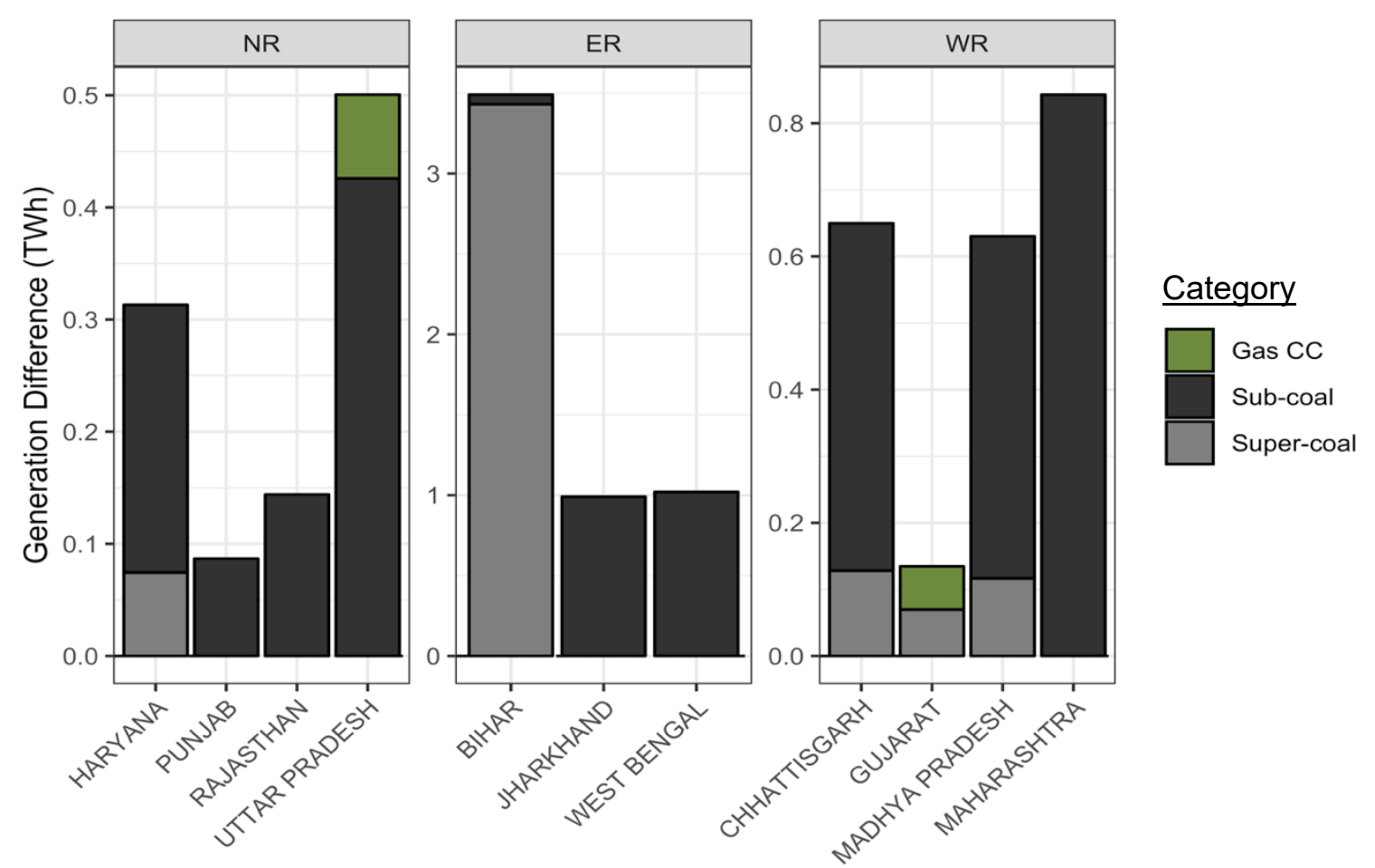

Figure 16. Major changes in generation by region and state with an added Bangladesh supply contract (TWh).

Note: Charts are based on Coordinated Operations and high buildout of hydropower in Nepal. Each region has its own vertical axis scale to illustrate scenario differences.

The largest single increase in coal generation occurs in Bihar, where generation from supercritical coal plants increases by nearly 3.5 TWh (69\%). Jharkhand and West Bengal—on the path between Bihar and Bangladesh-increase generation from subcritical coal plants by 2 TWh $(2 \%)$.

Additional demand in Bangladesh has a muted impact on generation in Uttar Pradesh and the states in India's Northern region. Total generation increases by about $1 \mathrm{TWh}(<1 \%)$ in Uttar Pradesh, Haryana, Rajasthan, and Punjab.

A related effect is a 2.2 TWh $(0.4 \%)$ generation increase in the Western region, including the states of Maharashtra, Chhattisgarh, and Madhya Pradesh. These three states have some of the lowest-cost coal resources in the country and are among India's largest power producing regions, generating about $30 \%$ of the country's electricity. The observed increase in generation is likely 
affected by the complex network of resources within India, as the system settles on a different equilibrium state with the additional load in Bangladesh.

\subsubsection{Energy Flow between Nepal, India, and Bangladesh}

Adding a supply contract with Bangladesh (dispatched through West Bengal) has very little effect on the amount of hydropower generated in Nepal and sent to India. With the supply contract, exports increase by $0.02 \mathrm{TWh}$, less than $0.5 \%$. The strongest effects occur within India, as generation and energy flows within India's Eastern region are redirected to move 8.7 TWh into Bangladesh (Figure 17).

With the supply contract, exports from Jharkhand, Assam, Sikkim, and Uttar Pradesh are redirected to Bangladesh via West Bengal. West Bengal and Jharkhand both decrease exports to Bihar in order to supply Bangladesh. As a result, Bihar must increase its internal generation by 3.5 TWh to meet demand.

Including Bangladesh did not impact the seasonal or daily patterns of trade between India and Nepal observed in Section 3.2.

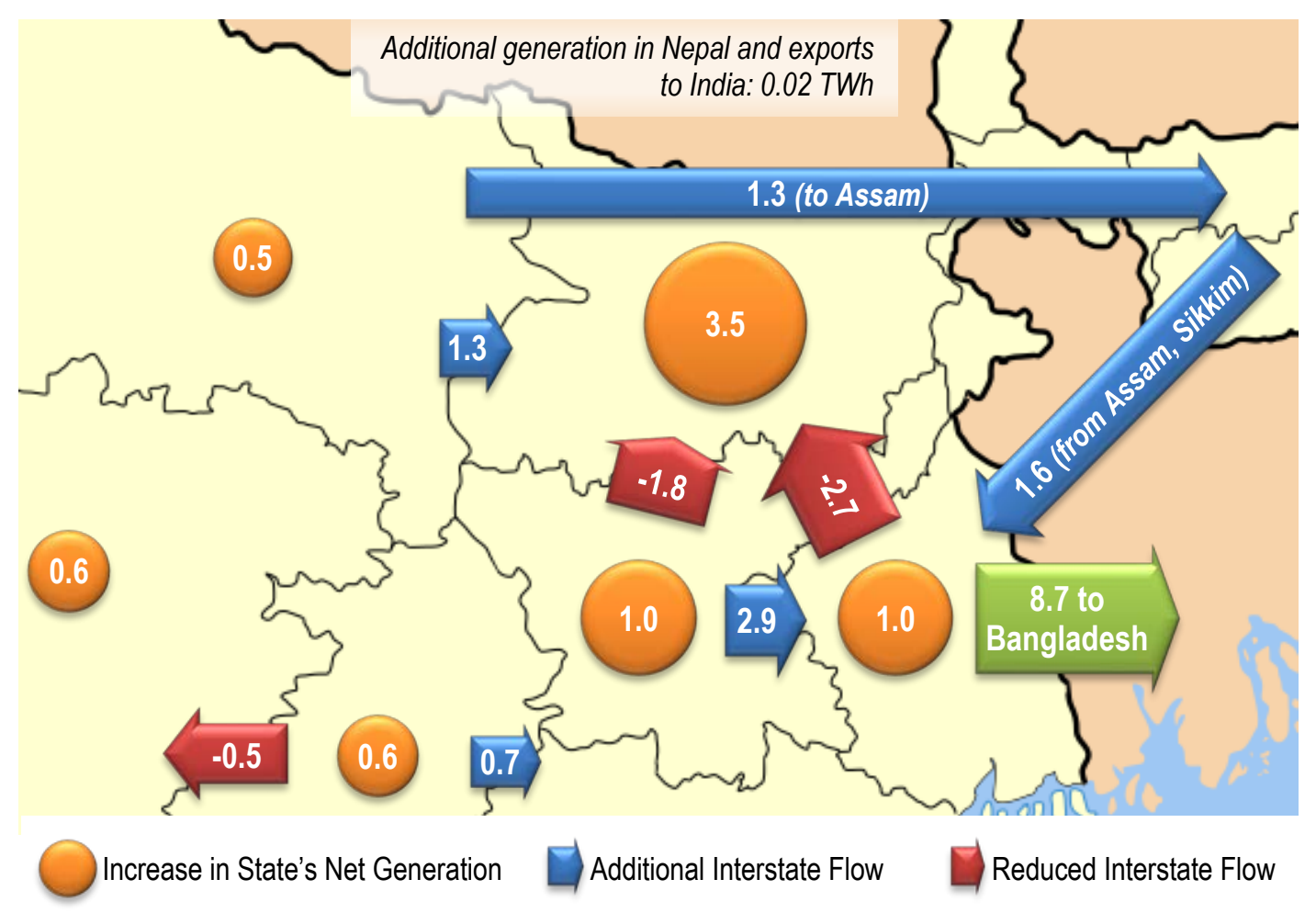

Figure 17. Major changes to India's internal annual interstate flows and generation after adding Bangladesh supply contract (TWh).

Note: Changes less than 0.5 TWh not shown, except for Nepal. 


\subsubsection{Transmission Congestion}

Including Bangladesh does result in a small increase in the number of hours congested between Nepal and Bihar and Nepal and Uttarakhand. As in Section 3.2, transmission congestion between Nepal and India occurs only on the $132-\mathrm{kV}$ lines, not on the larger 400-kV lines. Table 18 shows the number of hours transmission is congested congestion between Nepal and each Indian state.

Table 18. Transmission Congestion between Nepal and Neighboring Indian States, High Build-CO Scenarios with and without Bangladesh (hours)

\begin{tabular}{lcc}
\hline Interface & High Build-CO & Bangladesh-CO \\
\hline Nepal - Bihar & 5,541 & 5,879 \\
Nepal - Uttar Pradesh & 0 & 0 \\
Nepal - Uttarakhand & 1,900 & 1,928 \\
\hline
\end{tabular}

\subsection{Full Regional Integration}

As a final test, we compared some of the previous results against a scenario that is based on a theoretical independent system operator (ISO) comprising Bangladesh, Bhutan, India's Eastern LDC region, and Nepal (BBIN). The purpose of this scenario is to provide an ideal and ambitious benchmark of least-cost generation dispatch for comparison. The other scenarios described previously in this chapter address issues arising in current and recent CBET discussions among India, Nepal and Bangladesh. This ISO scenario, which assumes full coordination (i.e., no hurdle rates) and full security-constrained unit commitment and economic dispatch within the BBIN region, helps compare the results of these other scenarios with benefits that are theoretically achievable with perfect coordination across the power systems.

India's Eastern LDC region includes the states of Bihar, Jharkhand, West Bengal, Odisha, and Sikkim. The region borders Nepal, Bangladesh, and Bhutan. Modeling these areas as a hypothetical ISO means that energy would flow among these countries and states as easily as it would if the region were one state with one independent grid operator. We operationalize this assumption in the model by removing all hurdle rates between countries and states within the BBIN region. The hurdle rates between all other Indian states remains the same (INR 1,000 per $\mathrm{MWh}$ ), and is applied to transfers between the ISO and non-ISO Indian states.

To evaluate how additional CBET benefits resulting from Coordinated Operations between Nepal and India compare with the benefits that might be achievable under full market integration, the relevant comparisons are with scenarios that include exports to Bangladesh. Table 19 summarizes the scenarios included in this part of the analysis. 
Table 19. Scenarios in the Analysis

\begin{tabular}{lcccc}
\hline Scenario & Hydro Buildout & Hurdle Rates & $\begin{array}{c}\text { India Wind and } \\
\text { Solar Capacity }\end{array}$ & Bangladesh \\
\hline Bangladesh-BAU & High & BAU & & \\
Bangladesh-CO & $(4,551 \mathrm{MW})$ & $\begin{array}{c}\text { Coordinated Operations } \\
\text { None within ISO }\end{array}$ & $160 \mathrm{GW}$ & Included \\
BBIN ISO & & Non & & \\
\hline
\end{tabular}

In the BBIN ISO scenario, Bangladesh and Bhutan are represented only as described in Section 2.4 - net imports from Bhutan and the 1,000 MW export to Bangladesh - not their full systems. More detailed modeling of these systems is possible but is beyond the scope of this analysis.

\subsubsection{Electricity Production Cost}

Table 20 summarizes the changes in total generation and total production cost progressing from current BAU to Coordinated Operations, and from Coordinated Operations to full market integration in an ISO. Here we consider the impact on BBIN countries and states independent of the rest of India to highlight changes within the ISO that may be obscured when considering all of India together.

Table 20. Generation and Production Cost Differences between ISO Scenarios

\begin{tabular}{|c|c|c|c|c|c|}
\hline & Bangladesh-BAU & Bangladesh-CO & BBIN ISO & $\begin{array}{l}\text { Change, } \\
\text { BAU to CO }\end{array}$ & $\begin{array}{l}\text { Change, } \\
\text { CO to ISO }\end{array}$ \\
\hline \multicolumn{6}{|c|}{ Total Generation (TWh) } \\
\hline BBIN & 215 & 221 & 225 & $2.8 \%$ & $1.8 \%$ \\
\hline Rest of India & 1,450 & 1,444 & 1,440 & $-0.4 \%$ & $-0.3 \%$ \\
\hline \multicolumn{6}{|c|}{ Total Production Cost (USD million) } \\
\hline BBIN & $\$ 7,458$ & $\$ 7,249$ & $\$ 7,301$ & $-2.8 \%$ & $0.7 \%$ \\
\hline Rest of India & $\$ 40,872$ & $\$ 40,574$ & $\$ 40,439$ & $-0.7 \%$ & $-0.3 \%$ \\
\hline \multicolumn{6}{|c|}{ Total Production Cost (USD per MWh) } \\
\hline BBIN & $\$ 34.67$ & $\$ 32.78$ & $\$ 32.42$ & $-5.4 \%$ & $-1.1 \%$ \\
\hline Rest of India & $\$ 28.19$ & $\$ 28.10$ & $\$ 28.09$ & $-0.3 \%$ & negligible \\
\hline
\end{tabular}

Moving from BAU to Coordinated Operations simultaneously increases generation and reduces total costs within the BBIN region. As detailed in Section 3.2, more coordination result in less hydropower curtailment in Nepal, the movement of more hydropower across the border from Nepal into India, and the replacement of relatively high-cost thermal generation in India. 
The additional step from Coordinated Operations to a full ISO leads to more production within the ISO and commensurately less generation in the rest of India. While the BBIN ISO's total production cost increases because of this increased generation, its total cost per MWh generated falls $1.1 \%$ compared to Coordinated Operations. The additional increment of generation obtained by moving from Coordinated Operations to a BBIN ISO — slightly more than 4 TWh, or $1.8 \%$ costs $\$ 12.69$ per MWh, compared to an annual average of $\$ 32.78$ per MWh in the region with Coordinated Operations alone. Coordinated Operations and further integration to BBIN ISO reduces total generation costs per MWh everywhere, although the effect outside the BBIN area is comparatively small.

These numbers suggest that Coordinated Operations between Nepal and India—arguably a less complicated proposition than creating an ISO - can capture most of the economic benefits that are theoretically achievable but currently unrealized. Measured in cost per MWh generated within the BBIN area, Coordinated Operations can achieve 5.4\% of the theoretically possible $6.5 \%$ in unrealized savings.

\subsubsection{Electricity Generation by Resource}

Similar to the Bangladesh scenarios, a BBIN ISO does little to increase the utilization of Nepal's hydropower plants above what is observed under Coordinated Operations. Network congestion and seasonal capacity factors, rather than hurdle rates, limit Nepal's hydropower exports. Given these constraints, further reductions in hurdle rates in the BBIN ISO scenario have no impact on Nepal's hydropower generation and total exports.

Figure 18 shows the change in annual generation between the Bangladesh BAU, Bangladesh Coordinated Operations, and BBIN ISO scenarios for dispatch regions within the ISO and the rest of India. While the magnitude of decreased coal generation in India remains constant across the Coordinated Operations and BBIN ISO scenarios, the actual plants that are being displaced are not the same. In the BBIN ISO scenario, consolidating operations among states in India's Eastern region allows for greater utilization of the most efficient generators in that region. More expensive supercritical coal plants in Bihar are displaced by less expensive subcritical coal plants in Odisha and Jharkhand. Also, some subcritical coal generation from BBIN becomes cost effective enough to replace nearly $4 \mathrm{TWh}$ of coal generation in the rest of India. 

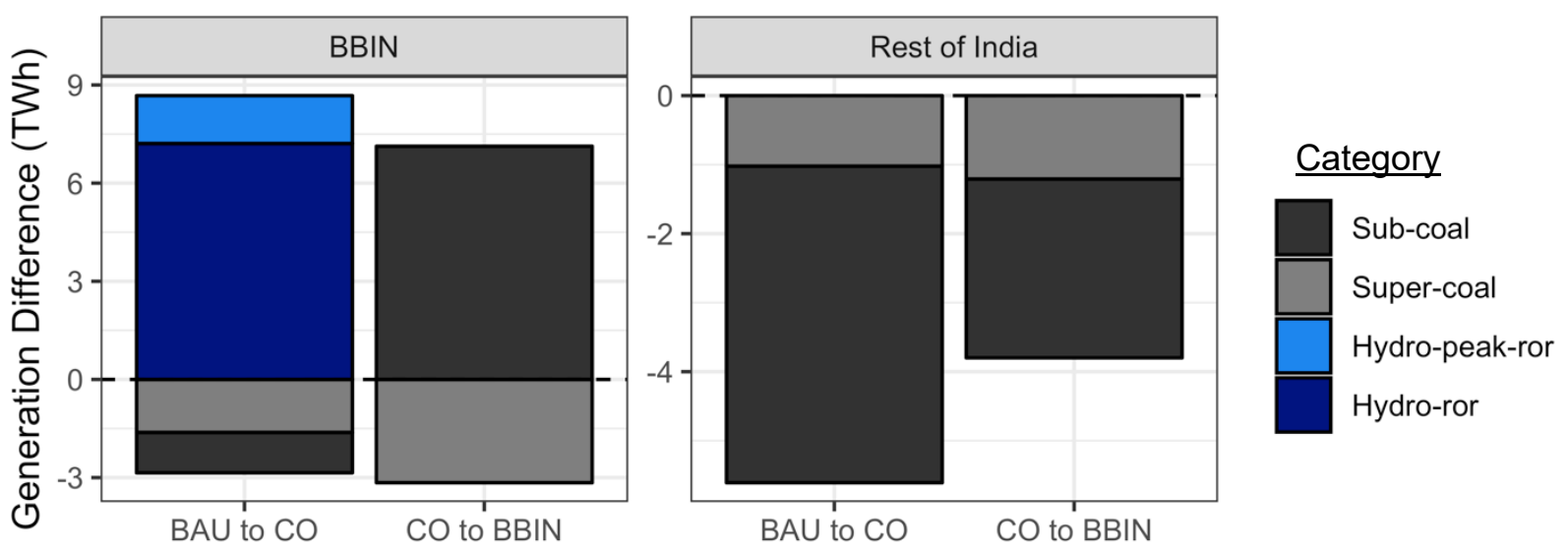

Figure 18. Change in annual generation for the BBIN region and the rest of India under different wheeling charge scenarios

\subsubsection{Energy Flow between Nepal and India}

Consolidation into a single market causes a net redistribution of about 5 TWh of generation among states and countries within the BBIN footprint. The result is a $12 \%$ increase in flows among these states and countries, accompanying the $4.1 \mathrm{TWh}$ increase in generation shown in Table 20. Most of the shift in interstate flows - 4.4 TWh-consists of additional transfers from Jharkhand and West Bengal to Bihar.

Overall, an ISO scenario puts the BBIN region in a stronger export position. Costs per MWh generated within the ISO decrease more than in the rest of India, making more BBIN resources economically competitive in India. While the BBIN region remains a net importer, the combined ISO increases its exports to the rest of India by about $4.4 \mathrm{TWh}$, or $20 \%$. Nearly all of these additional exports are from Odisha, a state with low-cost coal, to its neighboring states in the Southern region-Andhra Pradesh and Karnataka. Net transfers to the BBIN region increase by a modest $2 \%$, or $0.4 \mathrm{TWh}$. Flows from Chhattisgarh to Odisha and Jharkhand drop by $2.1 \mathrm{TWh}$, while flows from Assam to West Bengal and Bhutan increase 1.2 TWh. The BBIN ISO scenarios did not impact the seasonal or daily patterns of trade between India and Nepal as observed in Section 3.2.

\subsubsection{Transmission Congestion}

The largest increase in transmission congestion between Nepal and India occurs when changing from BAU to Coordinated Operations. Going further to a BBIN ISO adds slightly- $4.6 \%$ - to the congestion within the ISO between Nepal and Bihar. Table 21 shows the hours of congestion across each interface between Nepal and India. As in other scenarios, the congestion is limited to the $132-\mathrm{kV}$ connections between Nepal and India. 
Table 21. Transmission Congestion between Nepal and Neighboring Indian States, All Scenarios (hours)

\begin{tabular}{lccc}
\hline Interface & Bangladesh-BAU & Bangladesh-CO & BBIN ISO \\
\hline Nepal - Bihar & 1,703 & 5,879 & 6,160 \\
Nepal - Uttar Pradesh & 0 & 0 & 0 \\
Nepal - Uttarakhand & 204 & 1,928 & 1,923 \\
\hline
\end{tabular}




\section{Summary}

The model results indicate significant opportunities for increased trade between Nepal and India, particularly for India's Eastern and Northern LDC areas. Excess hydropower from Nepal tends to displace more expensive thermal generation in India. Future CBET will depend highly both on the level of Nepal's hydro buildout and level of coordination for power exchanges between the two countries.

Increased hydro buildout in Nepal. In the High Build scenario, where Nepal's hydropower capacity is 4,551 MW, production costs in the combined India and Nepal system could fall by $\$ 106$ million per year, or $0.3 \%$. The increased hydro capacity would allow Nepal to increase its annual exports to India by $60 \%$. Under existing levels of coordination, however, Nepal's run-ofriver plants are not fully utilized. Nepal's domestic load cannot absorb all of the increased hydro generation, and institutional hurdles between it and India make it uneconomic for Nepal to generate power for export during significant periods of the year such that $45 \%$ of available energy from hydropower is curtailed.

Coordinated operations. Nepal's high-buildout hydro resources are almost fully used if operations between Nepal and India are more coordinated, such that trade with Nepal is institutionally no different than trades between Indian states. The increased generation from hydro translates to decreased total annual production costs. With both Coordinated Operations, annual production costs in India and Nepal decrease $\$ 356$ million, or 1.0\%, compared to the High-BAU scenario. Combining increased hydro buildout in Nepal with Coordinated Operations would allow Nepal to become a net exporter during the dry season as well as the wet season. Lower cost generation also expands economic opportunities for Nepal to compete with India's Western region as a supplier of energy to the Northern region. As a result, in the High Build scenario with Coordinated Operations, coal generation in India's Western region decreases by $3.8 \mathrm{TWh}$, or $3.5 \%$ compared to the High Build scenario under BAU .

Integrating India's wind and solar resources. Greater hydro exports from Nepal to India appear to have little effect on integrating wind and solar in India, largely because most of the new hydro in Nepal is run-of-river hydro, which lacks storage. However, greater development of wind and solar resources in India can reduce the potential market for Nepal hydro unless institutional barriers to trade are reduced through coordinated operations. Wind and solar add zero marginal cost generation to India's mix, which affects the periods when hydro exports from Nepal to India are economic under BAU conditions. However, this impact becomes negligible under Coordinated Operations, which enable Nepal's hydro to compete economically despite the periods of lower marginal cost generation. As enabled by the hydro capacity in Nepal that does have storage, the profile of these exports tends to shift towards the evening hours to accommodate India's additional solar generation. India's curtailment of wind and solar at higher penetrations appears to be little changed by levels of trade between Nepal and India.

Nepal hydro to Bangladesh. Including a supply contract with Bangladesh increases total production costs in the region due to overall greater levels of electricity generation but adding supply to Bangladesh does not materially change Nepal's generation or exports under Coordinated Operations. Most of Nepal's plants are already operating at their maximum allowable output, and only a small fraction are constrained by transmission congestion within 
Nepal or between Nepal and India. Therefore, contractually obligating some amount of Nepal hydropower to Bangladesh essentially redirects power flows internally within India, particularly from added coal generation.

Consolidating system operations across Bangladesh, Bhutan, Nepal, and India's Eastern region does increase savings compared to BAU operations. Costs per MWh in the region fall by 5.4\% under Coordinated Operations, and by an additional 1.1\% if operations are fully consolidated within an independent system operator. With greater internal efficiency, the BBIN region also exports more power to the rest of India.

This study examines the operational impacts of CBET between India, Nepal, Bhutan, and Bangladesh and finds significant opportunities for increased trade and production cost savings. Complementary analysis could identify policy and regulatory pathways to remove non-technical barriers to CBET and achieve these benefits. 


\section{References}

Asian Development Bank (ADB). "Cross-border power trading in South Asia: A technoeconomic rationale.” ADB South Asia Working Paper Series, No. 38, August 2015. https:/www.adb.org/sites/default/files/publication/173198/south-asia-wp-038.pdf.

ANI. 2018. "India questions viability of Butwal-Gorakhpur power line." Business Standard, January 29, 2018. https://www.business-standard.com/article/news-ani/india-questions-viabilityof-butwal-gorakhpur-power-line-118012901543_1.html.

CEA (Central Electricity Authority), 2017a. All India Installed Capacity (in MW) of Power Stations (As on 31.12.2017) Revised. New Delhi: CEA. http://cea.nic.in/reports/monthly/installedcapacity/2017/installed_capacity-12.pdf.

CEA (Central Electricity Authority). 2017b. Report on $19^{\text {th }}$ Electric Power Survey of IndiaVolume I. New Delhi: CEA.

CEA (Central Electricity Authority). 2018. All India Installed Capacity (in MW) of Power Stations (as on 30.04.2018). New Delhi: CEA. http://www.cea.nic.in/reports/monthly/installedcapacity/2018/installed_capacity-04.pdf.

Joint Technical Team (JTT) of India and Bangladesh. 2016. Report on the feasibility of additional interconnection between India and Bangladesh. New Delhi: CEA. http://www.cea.nic.in/reports/committee/scm/ner/agenda_note/annex3.pdf.

Ministry of External Affairs (MEA), 2016. Amendment No. 9. Tender No. MEAINPT/2014/02 dated November 17, 2014. Development Partnership Administration, MEA.

Nepal Electricity Authority (NEA). 2017. Annual Report. Katmandu, Nepal. https://nea.org.np/admin/assets/uploads/supportive_docs/87757284.pdf.

Nepal Electricity Authority (NEA). 2018a. "Powerhouses.” Accessed January 26, 2018. http://www.nea.org.np/generation/index.php.

Nepal Electricity Authority (NEA). 2018b. "Kulekhani-I Hydropower Station.” Accessed January 26, 2018. http://www.nea.org.np/generation/index.php?page=powerhouse\&pid=16.

Palchak D., Cochran J., Deshmukh R., Ehlen A., Soonee S.K., Narasimhan S.R., Joshi M., McBennett B., Milligan M., Chernyakhovskiy I., and Sreedharan P., Abhyankar N. 2017. "Greening the grid: Pathways to Integrate 175 Gigawatts of Renewable Energy into India's Electric Grid, Vol. I-National Study.” National Renewable Energy Laboratory (NREL), Lawrence Berkeley National Laboratory (Berkeley Lab), Power System Operation Corporation Limited (POSOCO) and U.S. Agency for International Development (USAID). https://www.nrel.gov/docs/fy17osti/68530.pdf.

Power Technology (PT). 2018. "Siemens commissions HVDC back-to-back link in Bangladesh." Accessed December 31, 2018. https://www.power-technology.com/news/siemens-commissionshvdc-back-back-link-india-bangladesh/. 
Shrestha, P. 2016. "Cross-border transmission line between Nepal and India: a test-case for the analysis of HVDC integration into an existing HVAC system." Master's thesis, Norwegian University of Science and Technology, 2016. http://hdl.handle.net/11250/2387246.

South Asian Regional Initiative for Energy Integration and Integrated Research and Action for Development (SARI/EI and IRADe). 2017. "Economic Benefits from Nepal-India Electricity Trade."

Tanahu Hydropower Limited (THL). 2018. "Salient Features." Accessed January 26, 2018. http://www.thl.com.np/index.php?nav=salient.

Water and Energy Commission Secretariat (WECS). 2017. "Electricity Demand Forecast Report (2015-2040)." Government of Nepal.

World Bank (WB). 2015. "How much could South Asia benefit from regional electricity cooperation and trade." Policy Research working paper; no. WPS 7341. Washington, D.C.: World Bank Group. http://documents.worldbank.org/curated/en/846141468001468272/Howmuch-could-South-Asia-benefit-from-regional-electricity-cooperation-and-trade. 